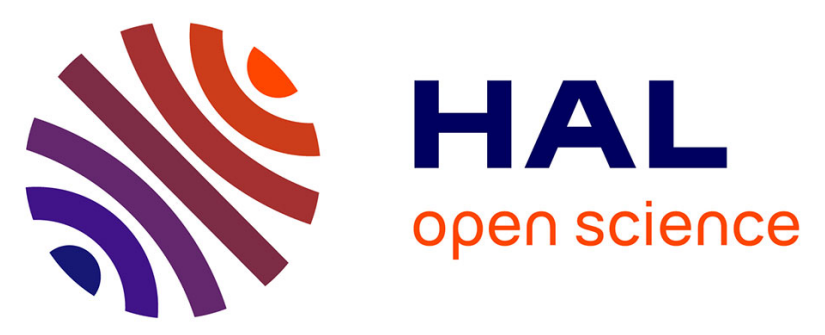

\title{
Reactions of Atomic Carbon with Butene Isomers: Implications for Molecular Growth in Carbon-Rich Environments
}

Jérémy Bourgalais, Michael Spencer, David L. Osborn, Fabien Goulay, Sébastien D. Le Picard

\section{To cite this version:}

Jérémy Bourgalais, Michael Spencer, David L. Osborn, Fabien Goulay, Sébastien D. Le Picard. Reactions of Atomic Carbon with Butene Isomers: Implications for Molecular Growth in Carbon-Rich Environments. Journal of Physical Chemistry A, 2016, 120 (46), pp.9138-9150. 10.1021/acs.jpca.6b09785 . hal-01437440

HAL Id: hal-01437440

https://hal-univ-rennes1.archives-ouvertes.fr/hal-01437440

Submitted on 10 Jul 2017

HAL is a multi-disciplinary open access archive for the deposit and dissemination of scientific research documents, whether they are published or not. The documents may come from teaching and research institutions in France or abroad, or from public or private research centers.
L'archive ouverte pluridisciplinaire HAL, est destinée au dépôt et à la diffusion de documents scientifiques de niveau recherche, publiés ou non, émanant des établissements d'enseignement et de recherche français ou étrangers, des laboratoires publics ou privés. 


\title{
Reactions of Atomic Carbon with Butene Isomers: Implications for Molecular Growth in Carbon-Rich Environments
}

\author{
J. Bourgalais ${ }^{1}$, Michael Spencer, ${ }^{2}$ David L. Osborn, ${ }^{3}$ F. Goulay ${ }^{2}{ }_{*}$ and S. D. Le Picard ${ }^{1, *}$ \\ ${ }^{1}$ Institut de Physique de Rennes, Département de Physique Moléculaire, Astrophysique de Laboratoire, UMR \\ CNRS 6251, Université de Rennes 1, Campus de Baulieu, 35042 Rennes Cedex, France \\ ${ }^{2}$ Department of Chemistry, West Virginia University, Morgantown, West Virginia 26506, USA \\ ${ }^{3}$ Combustion Research Facility, Mail Stop 9055, Sandia National Laboratories, Livermore, California 94551, USA
}

\section{Corresponding Author: \\ *Fabien.Goulay@mail.wvu.edu \\ *Sebastien.le-picard@univ-rennes1.fr}

\begin{abstract}
Product detection studies of $\mathrm{C}\left({ }^{3} \mathrm{P}\right)$ atom reactions with butene $\left(\mathrm{C}_{4} \mathrm{H}_{8}\right)$ isomers (but-1-ene, cisbut-2-ene, trans-but-2-ene) are carried out in a flow tube reactor at $353 \mathrm{~K}$ and 4 Torr under multiple collision conditions. Ground state carbon atoms are generated by $248 \mathrm{~nm}$ laser photolysis of tetrabromomethane, $\mathrm{CBr}_{4}$, in a buffer of helium. Thermalized reaction products are detected using synchrotron tunable VUV photoionization and time of flight mass spectrometry. The temporal profiles of the detected ions are used to discriminate products from side or secondary reactions. For the $\mathrm{C}\left({ }^{3} \mathrm{P}\right)+$ trans-but-2-ene and $\mathrm{C}\left({ }^{3} \mathrm{P}\right)+$ cis-but-2-ene reactions, various isomers of $\mathrm{C}_{4} \mathrm{H}_{5}$ and $\mathrm{C}_{5} \mathrm{H}_{7}$ are identified as reaction products formed via $\mathrm{CH}_{3-}$ and $\mathrm{H}$-elimination. Assuming equal ionization cross sections for all $\mathrm{C}_{4} \mathrm{H}_{5}$ and $\mathrm{C}_{5} \mathrm{H}_{7}$ isomers, $\mathrm{C}_{4} \mathrm{H}_{5}: \mathrm{C}_{5} \mathrm{H}_{7}$ branching ratios of $0.63: 1$ and $0.60: 1$ are derived for the $\mathrm{C}\left({ }^{3} \mathrm{P}\right)+$ transbut-2-ene and the $\mathrm{C}\left({ }^{3} \mathrm{P}\right)+$ cis-but-2-ene reactions, respectively. For the $\mathrm{C}\left({ }^{3} \mathrm{P}\right)+$ but-1-ene reaction, two reaction channels are observed: the H-elimination channel, leading to the formation of the ethylpropargyl isomer, and the $\mathrm{C}_{3} \mathrm{H}_{3}+\mathrm{C}_{2} \mathrm{H}_{5}$ channel. Assuming equal ionization cross sections for ethylpropargyl and $\mathrm{C}_{3} \mathrm{H}_{3}$ radicals, a branching ratio of 1:0.95 for the $\mathrm{C}_{3} \mathrm{H}_{3}+\mathrm{C}_{2} \mathrm{H}_{5}$ and $\mathrm{H}+$ ethylpropargyl channels is derived. The experimental results are compared to previous $\mathrm{H}$-atom branching ratios and used to propose the most likely
\end{abstract}


mechanisms for the reaction of ground state carbon atoms with butene isomers.

\section{INTRODUCTION}

Carbon is the fourth most abundant element in the universe and unbounded carbon atoms have been detected in a wide range of environments, from interstellar media (dense and diffuse clouds, protoplanetary nebulae, circumstellar envelopes...) $)^{1-5}$ to planetary atmospheres (e.g. Mars, Venus, Titan) ${ }^{6-8}$ and plasmas. ${ }^{9-11}$ In these environments, their barrierless reactions ${ }^{12-35}$ with abundant saturated and unsaturated hydrocarbons, nitrogen bearing molecules, and small free radicals are expected to initiate the growth of complex molecules ${ }^{9,36,37}$ even at very low temperatures. ${ }^{12-14,33,34}$ Consequently, carbon atom reactions are expected to play a role in the formation of polycyclic aromatic hydrocarbons (PAHs), aerosols, and soot. ${ }^{9,36,37}$ Improving the accuracy of models trying to reproduce the chemistry of such environments requires a better understanding of the mechanisms of elementary reactions between carbon atoms and abundant hydrocarbons. This goal can be achieved by probing the products of these reactions experimentally and theoretically over a wide range of physical conditions.

Most of the previous research on $\mathrm{C}\left({ }^{3} \mathrm{P}\right)$ reactivity focused on reactions with hydrocarbons containing fewer than 4 carbon atoms, investigated using various experimental techniques such as crossed molecular beams, ${ }^{16,19-21,27,35,38,39}$ flow tubes, ${ }^{23,26,31,40}$ or CRESU experiments, ${ }^{13,14,41}$ often coupled with ab initio calculations. ${ }^{18,24,25}$ The accepted dominant reaction mechanism derived from these experiments is addition of the $\mathrm{C}\left({ }^{3} \mathrm{P}\right)$ to the hydrocarbon followed by the loss of a hydrogen atom or methyl group to form an open-shell molecule. ${ }^{23,40}$ For large unsaturated hydrocarbons such as butene isomers $\left(\mathrm{C}_{4} \mathrm{H}_{8}\right.$, exit channels other than $\mathrm{H}$-atom or $\mathrm{CH}_{3}$ loss may become accessible. ${ }^{23}$

Butene is one of the smallest hydrocarbons with structural isomers and is a good archetype molecule for the study of gaseous fuel reactivity. It is a negligible component in 
gasoline but is produced during the combustion of larger hydrocarbons. ${ }^{42-44}$ The high temperature $(>1200 \mathrm{~K})$ pyrolysis of butene isomers leads to the formation of reactive free radicals such as methyl $\left(\mathrm{CH}_{3}\right)$, propargyl $\left(\mathrm{C}_{3} \mathrm{H}_{3}\right)$ and allyl $\left(\mathrm{C}_{3} \mathrm{H}_{5}\right)$ and ultimately to the formation of larger molecules such as benzene and $\mathrm{C}_{5} \mathrm{H}_{6}$ isomers. ${ }^{45}$ Under plasma conditions, butene is known to decompose easily into $\mathrm{CH}_{\mathrm{x}}$ and $\mathrm{C}_{2} \mathrm{H}_{\mathrm{x}}(\mathrm{x}=1,2,3)$ species and is used as a source of carbon atoms. ${ }^{46}$ Butene isomers are also believed to play a role in the photochemistry of organic molecules in planetary atmospheres (e.g. Titan). ${ }^{47,48}$ They are expected to react rapidly with atoms such as $\mathrm{C}, \mathrm{O}$, or $\mathrm{N}$ and with small hydrocarbons radicals such as $\mathrm{CH}$ or $\mathrm{C}_{2} \mathrm{H}$. Although rate constants and product distributions of butene reactions have been shown to depend on the specific butene isomer, ${ }^{49}$ computational model of these environments do not consider isomeric $\mathrm{C}_{4} \mathrm{H}_{8}$ structures, likely leading to uncertainties in the derived abundances of large species. Atkinson \& Aschmann ${ }^{49}$ determined rate constants for the reactions of $\mathrm{OH}$ radical with but-1-ene, cis-but-2-ene, trans-but-2-ene and isobutene at $295 \pm 1 \mathrm{~K}$ to be $(3.13 \pm 0.16) \times 10^{-10} \mathrm{~cm}^{3}$ molecules $^{-1} \mathrm{~s}^{-1},(5.60 \pm 0.13) \times 10^{-10} \mathrm{~cm}^{3}$ molecules ${ }^{-1} \mathrm{~s}^{-1}$, $(6.39 \pm 0.13) \times 10^{-10} \mathrm{~cm}^{3}$ molecules $\mathrm{s}^{-1}$ and $(5.13 \pm 0.24) \times 10^{-10} \mathrm{~cm}^{3}$ molecules $\mathrm{s}^{-1}$, respectively. Loison et al. ${ }^{50}$ investigated the lighter products formed by the reaction of $\mathrm{OH}$ radicals with trans-but-2-ene, and but-1-ene in a fast flow reactor at room temperature. The branching fractions for the $\mathrm{H}$-atom abstraction channel were measured to be $8 \pm 3 \%$ for $\mathrm{OH}+$ but-1-ene, and $3 \pm 1 \%$ for $\mathrm{OH}+$ trans-but-2-ene. More recently Bouwman et al. ${ }^{51}$ investigated $\mathrm{C}_{2} \mathrm{H}$ radical reactions with butene isomers (but-1-ene, cis-but-2-ene, trans-but-2-ene and isobutene) in a Laval expansion at $79 \mathrm{~K}$. They found similar rate constants for all reactions (ca. $2 \times 10^{-10} \mathrm{~cm}^{3}$ molecules ${ }^{-1} \mathrm{~s}^{-1}$ ) in agreement with previous measurements performed at room temperature, ${ }^{52,53}$ but observed an isomer dependence of the reaction products. It is worth noting that this work also showed that the $\mathrm{C}_{2} \mathrm{H}+\mathrm{C}_{4} \mathrm{H}_{8}$ reactions contribute to molecular weight growth with formation of larger species (4-penten-1-yne, 3-penten-1-yne, 
2-methyl-1-buten-3-yne, 4-methyl-3-penten-1-yne) through methyl radical elimination in addition to H-atom elimination.

The reaction kinetics of $\mathrm{C}\left({ }^{3} \mathrm{P}\right)+$ butene isomers was first studied by Haider \& Husain $^{12}$ at room temperature in a slow flow reactor. They measured overall rate constants for reactions with but-1-ene, cis-but-2-ene and trans-but-2-ene of $(4.3 \pm 0.2) \times 10^{-10} \mathrm{~cm}^{3}$ molecule $\mathrm{s}^{-1},(3.2 \pm 0.2) \times 10^{-10} \mathrm{~cm}^{3}$ molecule $^{-1} \mathrm{~s}^{-1}$ and $(2.9 \pm 0.2) \times 10^{-10} \mathrm{~cm}^{3}$ molecule $^{-1} \mathrm{~s}^{-1}$ respectively. More recently, Loison \& Bergeat $^{23}$ measured an overall rate coefficient for the the $\mathrm{C}\left({ }^{3} \mathrm{P}\right)+$ trans-but-2-ene reaction of $(1.9 \pm 0.6) \times 10^{-10} \mathrm{~cm}^{3}$ molecule ${ }^{-1} \mathrm{~s}^{-1}$, which is a factor

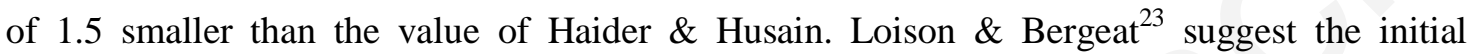
formation of a triplet $\mathrm{H}_{3} \mathrm{C}-\mathrm{HC} \bullet-\bullet \mathrm{C}=\mathrm{CH}-\mathrm{CH}_{3}$ adduct. From this intermediate, the accessible exothermic channels are $\mathrm{H}+\mathrm{C}_{5} \mathrm{H}_{7}$ and $\mathrm{CH}_{3}+\mathrm{C}_{4} \mathrm{H}_{5}$ through isomerization and $\mathrm{C}-\mathrm{H}$ or $\mathrm{C}-\mathrm{C}$ bond breaking, respectively. In addition Loison \& Bergeat measured an absolute atomic hydrogen branching fraction of $0.33 \pm 0.08$ using $\mathrm{H}$-atom resonance fluorescence. The authors stress the fact that the isomerization of the initial reaction adduct $\left(\mathrm{H}_{3} \mathrm{CHCCCHCH}_{3}\right)$ may greatly affect the final isomer distribution. Subsequently, Li et al. ${ }^{54}$ performed a theoretical study of the ground state carbon atom reaction with trans-but-2-ene by probing the complex triplet potential energy surface. They predict two major products: dimethylpropargyl $\left(\mathrm{H}_{3} \mathrm{CHCCCCH}_{3}\right)$ and a methylpropargyl isomer $\left(\mathrm{CH}_{3} \mathrm{CHCCH}\right)$, in agreement with Loison and Bergeat. ${ }^{23}$ The authors confirm a barrierless association reaction followed by isomerization and dissociation of the initial adduct. The large reaction rate coefficient measured at room temperature is therefore expected to remain high at low temperatures, making this reaction of interest for both interstellar medium and plasma assisted combustion chemistry.

The role of the $\mathrm{C}\left({ }^{3} \mathrm{P}\right)+$ butene reactions in gas phase environments depends on the importance of the $\mathrm{H}$ elimination exit channel relative to elimination of larger hydrocarbon 
radicals, as well as on the isomeric structure of the final products. If $\mathrm{C}_{5} \mathrm{H}_{7}$ isomers are produced, the reactions will contribute to the formation of long linear carbon chains in carbon rich environments. If $\mathrm{C}_{4} \mathrm{H}_{5}$ isomers are formed, the reactions could play a role in the chemical scheme leading to the formation of aromatic rings. ${ }^{55,56} \mathrm{C}_{4} \mathrm{H}_{5}$-isomers $\left(i-\mathrm{C}_{4} \mathrm{H}_{5}\right.$ and methylpropargyl isomers) have been observed both in fuel-rich flames ${ }^{57}$ and as $\mathrm{C}\left({ }^{3} \mathrm{P}\right)+$ propene reaction products. ${ }^{26,57}$ The reaction of acetylene $\left(\mathrm{C}_{2} \mathrm{H}_{2}\right)$ with the $i$ - $\mathrm{C}_{4} \mathrm{H}_{5}$ isomer is suggested as a possible route to benzene $\left(\mathrm{c}-\mathrm{C}_{6} \mathrm{H}_{6}\right)$ formation under certain flame conditions. ${ }^{58}$

The reaction would initially form fulvene $\left(\mathrm{c}-\mathrm{C}_{5} \mathrm{H}_{4}=\mathrm{CH}_{2}\right)$ which could then convert to benzene by $\mathrm{H}$-atom-assisted isomerization. ${ }^{59}$ The role of the methylpropargyl isomers $\left(\mathrm{CH}_{3} \mathrm{CHCCH}\right.$ and $\mathrm{CH}_{3} \mathrm{CCCH}_{2}$ ) in ring formation processes is still unknown and requires further investigation. For instance, $\mathrm{CH}_{3} \mathrm{CHCCH}$, is completely absent from flame models whereas $\mathrm{CH}_{3} \mathrm{CCCH}_{2}$ is suggested to form toluene $\mathrm{C}_{7} \mathrm{H}_{8}\left(\mathrm{C}_{6} \mathrm{H}_{5}-\mathrm{CH}_{3}\right)$ or benzyl radical $\mathrm{C}_{7} \mathrm{H}_{7}\left(\mathrm{C}_{6} \mathrm{H}_{5}-\right.$ $\left.\mathrm{CH}_{2}\right)$ by reaction with the propargyl radical $\left(\mathrm{CH}_{3} \mathrm{CCH}_{2}\right){ }^{60}$

In this work we present an investigation of the products formed by reactions of triplet ground state carbon atoms $\mathrm{C}\left({ }^{3} \mathrm{P}\right)$ with three butene isomers : but-1-ene, cis-but-2-ene and trans-but-2-ene. In order to probe the reaction products, experiments are performed in a flow tube reactor under multiple collision conditions ${ }^{26}$ (353 K \& 4 Torr) at the Advanced Light Source (ALS) synchrotron of Lawrence Berkeley National Laboratory. Detection of the products in the flow is carried out using tunable Vacuum Ultraviolet (VUV) photoionization and time of flight mass spectrometry. Kinetic traces and photoionization spectra supported by thermodynamic and Franck-Condon factor calculations of the $\mathrm{C}_{4} \mathrm{H}_{5}$ and $\mathrm{C}_{5} \mathrm{H}_{7}$ species have been used to infer the primary products of the reactions.

\section{EXPERIMETAL PROCEDURE}

A description of the apparatus has been given elsewhere ${ }^{61,62}$ and only a brief overview is presented here. Reactions are performed in a quartz flow tube with a length of $62 \mathrm{~cm}$ and 
$1.05 \mathrm{~cm}$ inner diameter. The gas pressure inside is typically 4 Torr with a total gas flow of $250 \mathrm{sccm}$ (standard cubic centimeters per minute). All experiments are carried out at $353 \mathrm{~K}$ corresponding to a total number density of $1.09 \times 10^{17} \mathrm{~cm}^{-3}$ and a slow flow velocity $\left(\sim 10 \mathrm{~m} \mathrm{~s}^{-}\right.$

$\left.{ }^{1}\right)$. The buffer gas (helium), carbon atom precursor $\left(\mathrm{CBr}_{4}\right)$ and reagent gas (butene isomers) are metered by mass-flow controllers. Reagent gases and the precursor were used without further purification: but-1-ene (> 99\%, Aldrich), cis-but-2-ene (> 99\%, Aldrich), trans-but-2ene (> 99\%, Aldrich) \& $\mathrm{CBr}_{4}\left(99 \%\right.$, Aldrich). $\mathrm{CBr}_{4}$ was introduced in the reactor with a typical density of $\sim 4 \times 10^{12} \mathrm{~cm}^{-3}$, by flowing a small amount of He over solid $\mathrm{CBr}_{4}$ upstream of the reaction tube. At $\sim 30 \mathrm{~cm}$ along the tube, a $650 \mu \mathrm{m}$ pinhole allows a small portion of the gas mixture to expand into a vacuum chamber. There, a skimmer generates a beam of molecules entering a differentially pumped ionization chamber in which molecular and atomic species are ionized by quasi-continuous VUV synchrotron radiation. Ions formed are detected using an orthogonal-acceleration time-of-flight mass spectrometer pulsed at $50 \mathrm{kHz}$. All detected ions are time-tagged relative to the excimer laser pulse (at $t=0$ ) operating at 10 $\mathrm{Hz}$ and accumulated in a transient digitizer to collect complete mass spectra as a function of time. It should be noted that the operation frequency of the laser allows sufficient time between laser pulses to completely refresh the gas mixture. The total ion detection timewindow is $50 \mathrm{~ms}$, beginning $10 \mathrm{~ms}$ before the laser pulse. Time-and energy-resolved mass spectra are obtained by averaging at least 500 laser shots at each photon energy. All data are normalized to account for variations in VUV photon flux using a NIST-calibrated photodiode (SXUV-100, International Radiation Detectors, Inc.). At each mass-to-charge $(\mathrm{m} / \mathrm{z})$ ratio, the average signal present before the laser pulse is subtracted from the time dependent data. The photoionization spectra at a given $\mathrm{m} / \mathrm{z}$ ratio are obtained by integrating the data set over the desired mass and time windows. The ionizing photon energy is scanned from 7.4 to $9.0 \mathrm{eV}$ in steps of $0.025 \mathrm{eV}$. $\mathrm{Kr}$ or $\mathrm{Ar}$ is used in a gas filter to absorb higher energy photons at 
harmonics of the undulator energy. Up to three independent datasets are recorded for each reaction and averaged. The photon energy resolution is determined to be of the order of 40 meV by measuring an atomic resonance of $\mathrm{Xe}$.

Carbon atoms were generated by $248 \mathrm{~nm}$ photolysis of $\mathrm{CBr}_{4}$, using a pulsed excimer $(\mathrm{KrF})$ laser operating at $10 \mathrm{~Hz}$. The laser power output is typically $266 \mathrm{~mJ}$ per pulse $(20 \mathrm{~ns})$, with a fluence inside the reaction flow tube of $\sim 20-50 \mathrm{~mJ} \mathrm{~cm}^{-2}$. The multiphoton photodissociation of $\mathrm{CBr}_{4}$ at $248 \mathrm{~nm}$ eliminates multiple halogen atoms, leading to the formation of carbon atoms ${ }^{62}$ and $\mathrm{CBr}$ radicals. ${ }^{63,64}$ Under our experimental conditions $20 \%$ of the introduced $\mathrm{CBr}_{4}$ is photodissociated. Shannon et al. ${ }^{63}$ determined a $\mathrm{C}\left({ }^{1} \mathrm{D}\right) / \mathrm{C}\left({ }^{3} \mathrm{P}\right)$ ratio following $\mathrm{CBr}_{4}$ photodissocation at $266 \mathrm{~nm}$ of $0.15 \pm 0.04$ at $296 \mathrm{~K}$. Molecular nitrogen is known to efficiently quench $C\left({ }^{1} \mathrm{D}\right)$ atoms through $\mathrm{C}\left({ }^{1} \mathrm{D}\right)+\mathrm{N}_{2}-7 \mathrm{C}\left({ }^{3} \mathrm{P}\right)+\mathrm{N}_{2}$ with a reaction rate coefficient of $k=5.3 \times 10^{-12} \mathrm{~cm}^{3}$ molecules ${ }^{-1} \mathrm{~s}^{-1} \cdot{ }^{65}$ In order to avoid potential chemical interferences from the reaction between $C\left({ }^{1} \mathrm{D}\right)$ and butene, the present experiments were performed using a large excess of $\mathrm{N}_{2}\left(1.8 \times 10^{16} \mathrm{~cm}^{-3}\right)$. In the present experimental conditions (353 K \& 4 Torr), for known densities of reactant $\left(\mathrm{C}_{4} \mathrm{H}_{8} \sim 10^{14} \mathrm{~cm}^{-3}\right)$ and considering a $\mathrm{C}\left({ }^{3} \mathrm{P}\right)$ $+\mathrm{C}_{4} \mathrm{H}_{8}$ reaction rate constant of $k=1.9 \times 10^{-10} \mathrm{~cm}^{3}$ molecules ${ }^{-1} \mathrm{~s}^{-1},{ }^{23}$ the characteristic decay times are calculated to be five times shorter for $C\left({ }^{1} \mathrm{D}\right)$ reaction with molecular nitrogen than for the $\mathrm{C}\left({ }^{3} \mathrm{P}\right)$ reaction with butene isomers. Consequently, in the following sections the influence of $\mathrm{C}\left({ }^{1} \mathrm{D}\right)$ atoms reactions with butene isomers is neglected. In addition, due to the high efficiency of $\mathrm{C}\left({ }^{3} \mathrm{P}\right)$ fine structure relaxation by collision with $\mathrm{He}$, the spin-orbit level population distribution of ground state carbon atoms, $\mathrm{C}\left(\stackrel{3}{\mathrm{P}}_{0,1,2}\right)$ in the flow tube are expected to be thermalized. ${ }^{13,66}$ The impact of $\mathrm{CBr}$ reactions with butene on product identification is discussed in the Results section. Finally, it is worth noting that the absorption cross-section of 1-butene was measured to be $6.8 \times 10^{-21} \mathrm{~cm}^{2}$ at $220 \mathrm{~nm},{ }^{67}$ likely leading to negligible dissociation of the butene isomers at the longer wavelength used here. 


\section{COMPUTATIONAL METHODS}

Electronic structure calculations of the neutral $\mathrm{C}_{5} \mathrm{H}_{7}$ species and their cations are carried out using the Gaussian09 package employing the B3LYP/CBSB7 method to obtain optimized geometries. Theoretical calculations with the same methods were applied for $\mathrm{C}_{4} \mathrm{H}_{5}$ isomers in a previous study. ${ }^{26}$ Heats of reaction and adiabatic and vertical ionization energies are obtained using the CBS-QB3 composite method. All the vibrational frequencies are real, indicating that the optimized geometries represent minima on the potential energy surface. Photoionization spectra of $\mathrm{C}_{5} \mathrm{H}_{7}$ isomers are calculated at $298 \mathrm{~K}$ using the $\mathrm{G} 09$ package within the Franck-Condon approximation. ${ }^{68}$ The simulated factors are convolved with a 40 $\mathrm{meV}$ (FWHM) Gaussian response function and integrated to simulate direct photoionization spectra.

\section{RESULTS}

Table 1 reports the optimized structures for seven $\mathrm{C}_{5} \mathrm{H}_{7}$ isomers together with their computed ionization energies. Because the cationic form of the cyclic isomer cannot be optimized, the value reported is the vertical ionization energ. As mentioned above, $\mathrm{C}_{4} \mathrm{H}_{5}$ isomers have been investigated in a previous study. ${ }^{26}$

Table 1 Optimized structures (B3LYP/CBSB7 method) and adiabatic ionization energies

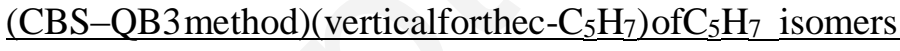

\begin{tabular}{|c|c|c|c|c|c|}
\hline Isomer & $\begin{array}{l}\text { Optimized } \\
\text { structure }\end{array}$ & $\begin{array}{c}\text { Ionization } \\
\text { energy } \\
(\mathrm{eV})\end{array}$ & Isomer & $\begin{array}{l}\text { Optimized } \\
\text { structure }^{a}\end{array}$ & $\begin{array}{c}\text { Ionization } \\
\text { energy } \\
(\mathrm{eV})\end{array}$ \\
\hline Trans $\mathrm{C}_{5} \mathrm{H}_{7}$ & & 7.10 & Ethylpropargyl & & 7.88 \\
\hline Cis $\mathrm{C}_{5} \mathrm{H}_{7}$ & & 7.19 & Trans $3-\mathrm{C}_{5} \mathrm{H}_{7}$ & & 7.40 \\
\hline Dimethylpropargyl & & 7.41 & Cis $3-\mathrm{C}_{5} \mathrm{H}_{7}$ & & 7.41 \\
\hline $\mathrm{c}-\mathrm{C}_{5} \mathrm{H}_{7}$ & & 8.19 & & & \\
\hline
\end{tabular}


Table 2 presents computed enthalpies of reaction at $298 \mathrm{~K}$ for all the predicted reaction channels and investigated $\mathrm{C}_{4} \mathrm{H}_{8}$ isomers. All of the reaction channels are found to be exothermic. The difference between isomers is outside the error of the method which is $\sim 5 \mathrm{~kJ}$ $\mathrm{mol}^{-1}$ on averaged prediction of $\Delta_{\mathrm{f}} \mathrm{H}^{\circ}(298.15 \mathrm{~K})$ for CBS-X methods. ${ }^{69}$ Within these uncertainties, the enthalpies of reaction displayed in Table 2 for the $\mathrm{C}\left({ }^{3} \mathrm{P}\right)+\operatorname{trans}-\mathrm{C}_{4} \mathrm{H}_{8}$ reaction are similar to those calculated by $\mathrm{Li}$ et al. (G3B3//B3LYP/6-311G(d,p)). ${ }^{54}$ These values are all lower than the enthalpies calculated by Loison and Bergeat based on experimental enthalpies of formation. ${ }^{23}$

Table $2 \Delta H_{r}(298 \mathrm{~K})^{\mathrm{a}}\left(\mathrm{kJ} \mathrm{mol}^{-1}\right)$ forpossiblereactionchannels of $\mathrm{C}\left({ }^{3} \mathrm{P}\right)+\mathrm{C}_{4} \mathrm{H}_{8}$.

\begin{tabular}{|c|c|c|c|}
\hline Channels & Trans $-\mathrm{C}_{4} \underline{\mathrm{H}}_{8}$ & 8 Cis $-\mathrm{C}_{4} \mathrm{H}_{8}$ & $1-\mathrm{C}_{4} \underline{\mathrm{H}}_{8}$ \\
\hline Trans $-\mathrm{C}_{5} \mathrm{H}_{7}+\mathrm{H}$ & -204.52 & -209.75 & -215.00 \\
\hline Cis $-\mathrm{C}_{5} \mathrm{H}_{7}+\mathrm{H}$ & -207.13 & -212.37 & -217.62 \\
\hline Dimethylpropargyl $+\mathrm{H}$ & -209.75 & -215.00 & -220.24 \\
\hline Ethylpropargyl $+\mathrm{H}$ & -199.26 & -204.51 & -209.75 \\
\hline $3-\mathrm{C}_{5} \mathrm{H}_{7}+\mathrm{H}$ & -201.89 & -207.13 & -212.37 \\
\hline$c-\mathrm{C}_{5} \mathrm{H}_{7}+\mathrm{H}$ & -49.82 & -55.06 & -60.30 \\
\hline$i-\mathrm{C}_{3} \mathrm{H}_{5}+\mathrm{CH}_{3}$ & -243.84 & -249.08 & -254.32 \\
\hline $\mathrm{CH}_{3} \mathrm{CHCCH}+\mathrm{CH}_{3}$ & -238.59 & -243.84 & -249.08 \\
\hline $\mathrm{CH}_{3} \mathrm{CCCH}_{2}+\mathrm{CH}_{3}$ & -249.08 & -254.32 & -259.57 \\
\hline $\mathrm{C}_{3} \underline{\mathrm{H}}_{3}+\mathrm{C}_{3} \underline{\mathrm{H}}_{5}$ & -236.64 & -247.66 & 14 \\
\hline
\end{tabular}

Photoion spectra were recorded with and without $\mathrm{CBr}_{4}$ and with or without the photolysis laser pulse. In the absence of butene in the reactor flow, no ion signals were detected at $m / z, 15,53$ and 67 , corresponding to the expected $\mathrm{C}\left({ }^{3} \mathrm{P}\right)+$ butene product masses $\left(\mathrm{CH}_{3}, \mathrm{C}_{4} \mathrm{H}_{5}\right.$ and $\left.\mathrm{C}_{5} \mathrm{H}_{7}\right)$. The reactivity of $\mathrm{CBr}$ radicals with butene isomers has to be considered to ensure that products formed at $\mathrm{m} / z 53$ and 67 do not originate from reactions involving $\mathrm{CBr}$. The rate coefficient of trans $-\mathrm{C}_{4} \mathrm{H}_{8}$ reaction with $\mathrm{CBr}$ has been determined by Ruzsicska et al. ${ }^{70}$ to be $1.23 \times 10^{-11} \mathrm{~cm}^{3}$ molecules ${ }^{-1} \mathrm{~s}^{-1}$, which is fifteen times lower than that of the $\mathrm{C}\left({ }^{3} \mathrm{P}\right)$ reaction with butene. ${ }^{23}$ Consequently, under the present experimental conditions, $\mathrm{CBr}+$ butene products are formed more slowly than the $\mathrm{C}\left({ }^{3} \mathrm{P}\right)+$ butene products. Previous 
investigations on the $\mathrm{C}\left({ }^{3} \mathrm{P}\right)+$ ethylene and $\mathrm{C}\left({ }^{3} \mathrm{P}\right)+$ propylene reactions have shown that such slower secondary processes and side reactions with characteristic times of the order of few hundreds of microseconds can be discriminated against primary processes by inspecting the product time traces. ${ }^{26}$ Furthermore, for all the results presented below, the contributions from slow reactions or subsequent reactions are minimized by integrating mass spectra only over the $0-1 \mathrm{~ms}$ time range.

In the sections below, we analyze mass spectra and photoionization spectra obtained upon irradiation of a mixture of $\mathrm{CBr}_{4}$ with three different butene isomers: but-1-ene, cis-but2-ene, trans-but-2-ene. Photoionization spectra acquired at 4 and 8 Torr do not show significant differences. In the following section only spectra recorded at 4 Torr are presented. Comparing photoionization spectra to previous results or to calculated photoionization spectra identifies the isomeric structure of the reaction products.

The time behavior of the non-normalized ion signal after the laser pulse is used to discriminate between $\mathrm{C}\left({ }^{3} \mathrm{P}\right)$ reaction products and products from side reactions as well as to infer product branching fractions. The signals $S_{i}$ for the main products are fitted using Eq. 1 corresponding to a pseudo-first order model of sequential reactions. ${ }^{71}$

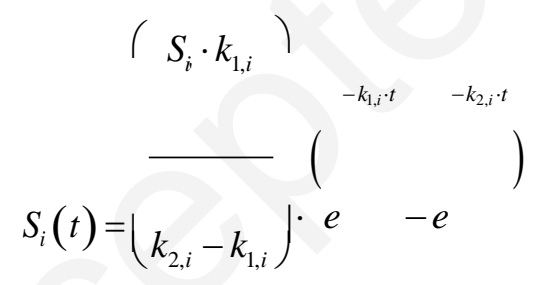

The coefficients $k_{1, i}$ and $k_{2, i}$ are the pseudo first order rate constants for the formation and loss of the product $i$. $S_{i}$ is proportional to the amount of reactants consumed to form product $i$. Branching ratios are obtained from the ratio of the $S_{i}$ values for two different channels assuming equal ionization cross sections.

\section{A. $\left.C^{3} \mathbf{P}\right)+$ trans-but-2-ene}


FIG. 1 displays the mass spectrum obtained following photolysis of a mixture of $\mathrm{CBr}_{4}$ and trans-but-2-ene in helium and nitrogen. The data are recorded at $9.0 \mathrm{eV}$ photon energy.

The negative signals at $\mathrm{m} / \mathrm{z} 28,41,56$ and 127 are due to imperfect subtraction of ion signal from butene or from impurities present in the reaction flow. Over the short reaction window (1 ms), the main ion signals are observed at $m / z 53,55,67,68,91,93,146,147,148 \& 149$. Products at $m / z 91 \& 93$ are identified to be $\mathrm{C}^{79} \mathrm{Br}$ and $\mathrm{C}^{81} \mathrm{Br}$, formed by photodissociation of $\mathrm{CBr}_{4}$ at $248 \mathrm{~nm}$.

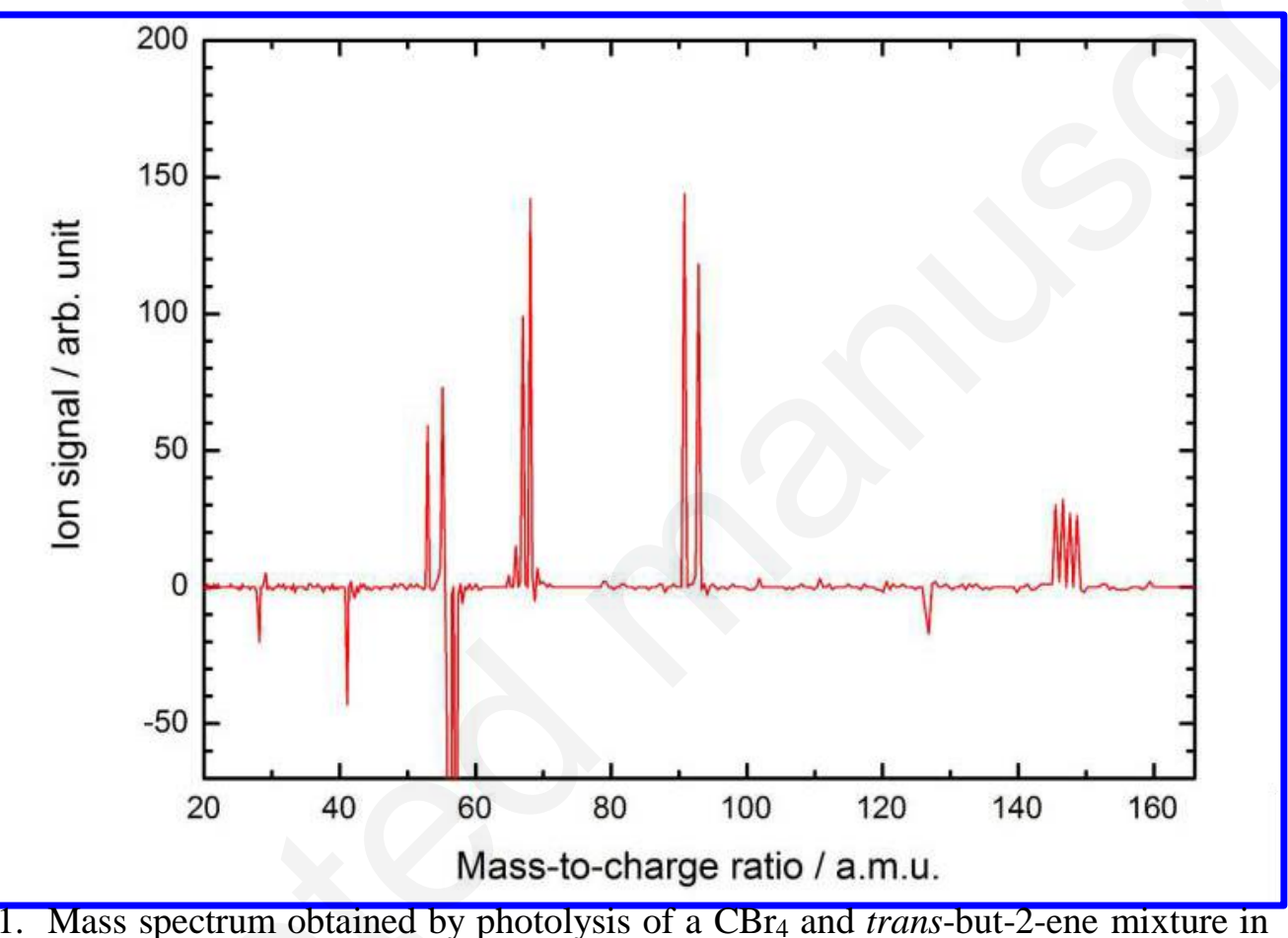

FIG. 1. Mass spectrum obtained by photolysis of a $\mathrm{CBr}_{4}$ and trans-but-2-ene mixture in helium at $9.0 \mathrm{eV}$ photon energy integrated over the $0-1 \mathrm{~ms}$ time range.

FIG. 2 shows the normalized averaged kinetic traces of $m / z$ 146/148 (red circles) and $\mathrm{m} / \mathrm{z}$ 147/149 (blue squares) together with modeled $\mathrm{C}_{4} \mathrm{H}_{7} \mathrm{Br}$ (red line) and $\mathrm{C}_{4} \mathrm{H}_{8} \mathrm{Br}$ (blue line) temporal traces. The m/z 147/149 and m/z 146/148 temporal profiles are modeled using the following scheme:

$$
\begin{array}{ll}
\mathrm{CBr}+\mathrm{C}_{4} \mathrm{H}_{8} & \rightarrow \mathrm{C}_{5} \mathrm{H}_{7} \mathrm{Br}+\mathrm{H} \\
\mathrm{CBr}+\mathrm{C}_{4} \mathrm{H}_{8} & \rightarrow \mathrm{C}_{5} \mathrm{H}_{8} \mathrm{Br} * \\
\mathrm{C}_{5} \mathrm{H}_{8} \mathrm{Br}^{*} & \rightarrow \mathrm{C}_{5} \mathrm{H}_{7} \mathrm{Br}+\mathrm{H}
\end{array}
$$


The metastable $\mathrm{C}_{5} \mathrm{H}_{8} \mathrm{Br}^{*}$ at $\mathrm{m} / \mathrm{z} 147 / 149$ is formed by the $\mathrm{CBr}+\mathrm{C}_{4} \mathrm{H}_{8}$ reaction (R1b) $\left(k_{1 \mathrm{a}+1 \mathrm{~b}}=1.23 \times 10^{-11} \mathrm{~cm}^{3} \text { molecules }{ }^{-1} \mathrm{~s}^{-1}\right)^{70}$ and decays $\left(k_{2}=500 \mathrm{~s}^{-1}\right)$ to give $\mathrm{C}_{5} \mathrm{H}_{7} \mathrm{Br}+\mathrm{H}(\mathrm{R} 2)$. The temporal profile for $\mathrm{C}_{5} \mathrm{H}_{7} \mathrm{Br}$ at $\mathrm{m} / \mathrm{z}$ 146/148 signal is the sum of the contributions from $\mathrm{CBr}+\mathrm{C}_{4} \mathrm{H}_{8}$ (R1a) and $\mathrm{C}_{5} \mathrm{H}_{8} \mathrm{Br}$ decomposition to $\mathrm{C}_{5} \mathrm{H}_{7} \mathrm{Br}+\mathrm{H}$ (R2). The data are best reproduced with branching ratios of $0.5-0.6$ for reaction $\mathrm{R} 1 \mathrm{a}$ and $0.5-0.4$ for reaction $\mathrm{R} 1 \mathrm{~b}$.

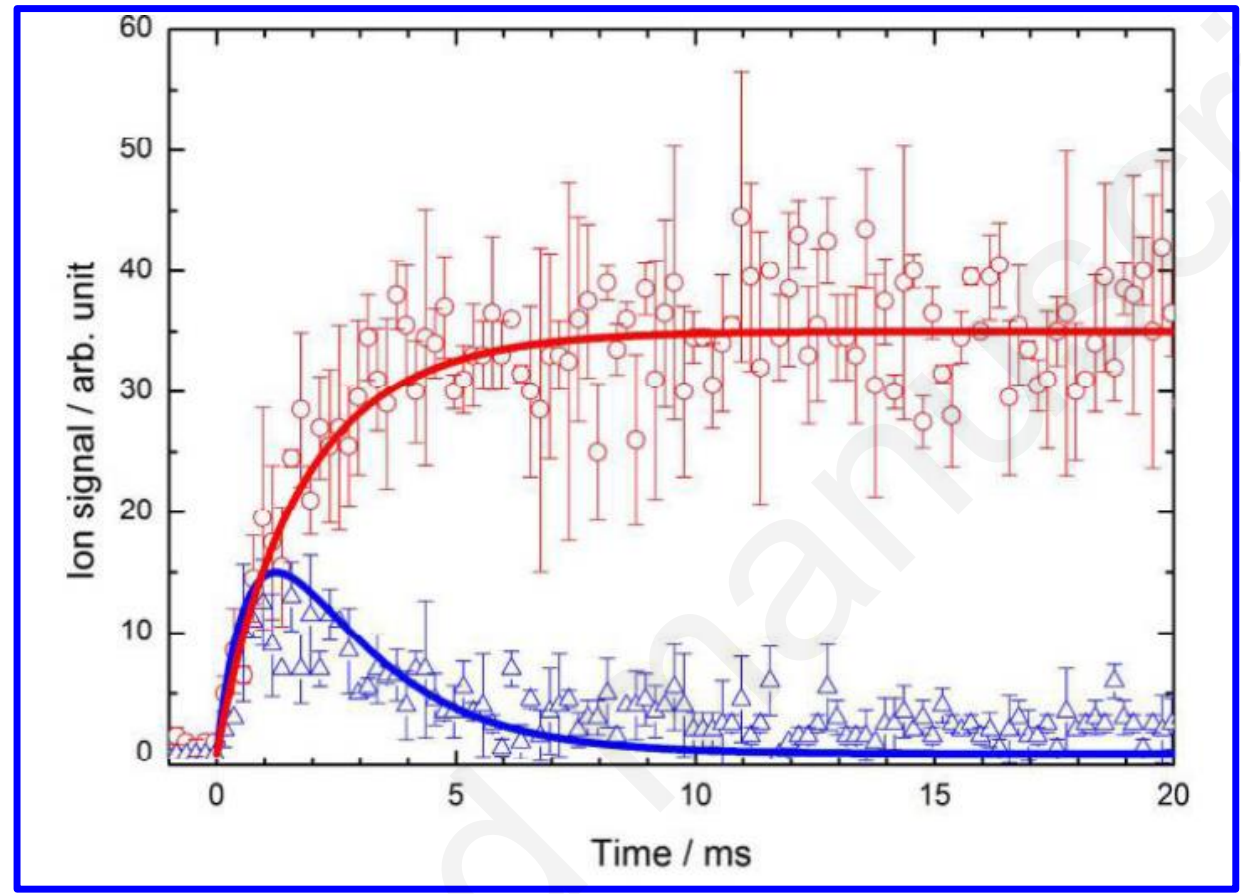

FIG. 2. Normalized averaged kinetic traces of $m / z, 146 / 148$ (red circles) and m/z 147/149 (blue squares) obtained by photolysis of a $\mathrm{CBr}_{4}$ and trans-but-2-ene mixture in helium, at 9.0 $\mathrm{eV}$ photon energy. The thick lines are modeled traces for $\mathrm{C}_{5} \mathrm{H}_{7} \mathrm{Br}$ (red line) and $\mathrm{C}_{5} \mathrm{H}_{8} \mathrm{Br}$ (blue line).

FIG. 3 shows the normalized temporal traces of (a) $\mathrm{m} / z$ $53\left(\mathrm{C}_{4} \mathrm{H}_{5}\right.$, blue down triangles) and $67\left(\mathrm{C}_{5} \mathrm{H}_{7}\right.$, purple triangles), (b) $m / z 55\left(\mathrm{C}_{4} \mathrm{H}_{7}\right.$, cyan diamonds) and 67 (purple triangles), and (c) $m / z 68$ ( $\mathrm{C}_{5} \mathrm{H}_{8}$, dark yellow left triangles) and 67 (purple triangles). Thick blue, cyan and purple lines are double exponential fits to $m / z 53,55$ and 67 , respectively. The thick dark yellow line is a single exponential fit to $\mathrm{m} / \mathrm{z}$ 68. According to these kinetic traces, $m / z 53 \& 67$ are likely to be formed by the fast $\mathrm{C}\left({ }^{3} \mathrm{P}\right)+\mathrm{C}_{4} \mathrm{H}_{8}$ reaction, as suggested by the 
$350 \mu$ s time constant of the observed rise, corresponding to a large value of $k_{1 \mathrm{st}}\left(\geq 3500 \mathrm{~s}^{-1}\right)$. The diffusion corrected ${ }^{72,73}$ pseudo first order rate $\left(\sim 9,000 \mathrm{~s}^{-1}\right)$ is still lower than the predicted one $\left(19,000 \mathrm{~s}^{-1}\right)$, likely due to the instrument response function. Here we assume that the rising edges of these two signals represent creation of $\mathrm{C}_{4} \mathrm{H}_{5}$ and $\mathrm{C}_{5} \mathrm{H}_{7}$. By contrast, the kinetic traces of $m / z 55 \& 68$ show a slower increase $\left(k_{1 \mathrm{st}} \sim 1000 \mathrm{~s}^{-1}\right)$, suggesting that they are formed by reactions slower than $\mathrm{C}\left({ }^{3} \mathrm{P}\right)+\mathrm{C}_{4} \mathrm{H}_{8}$.

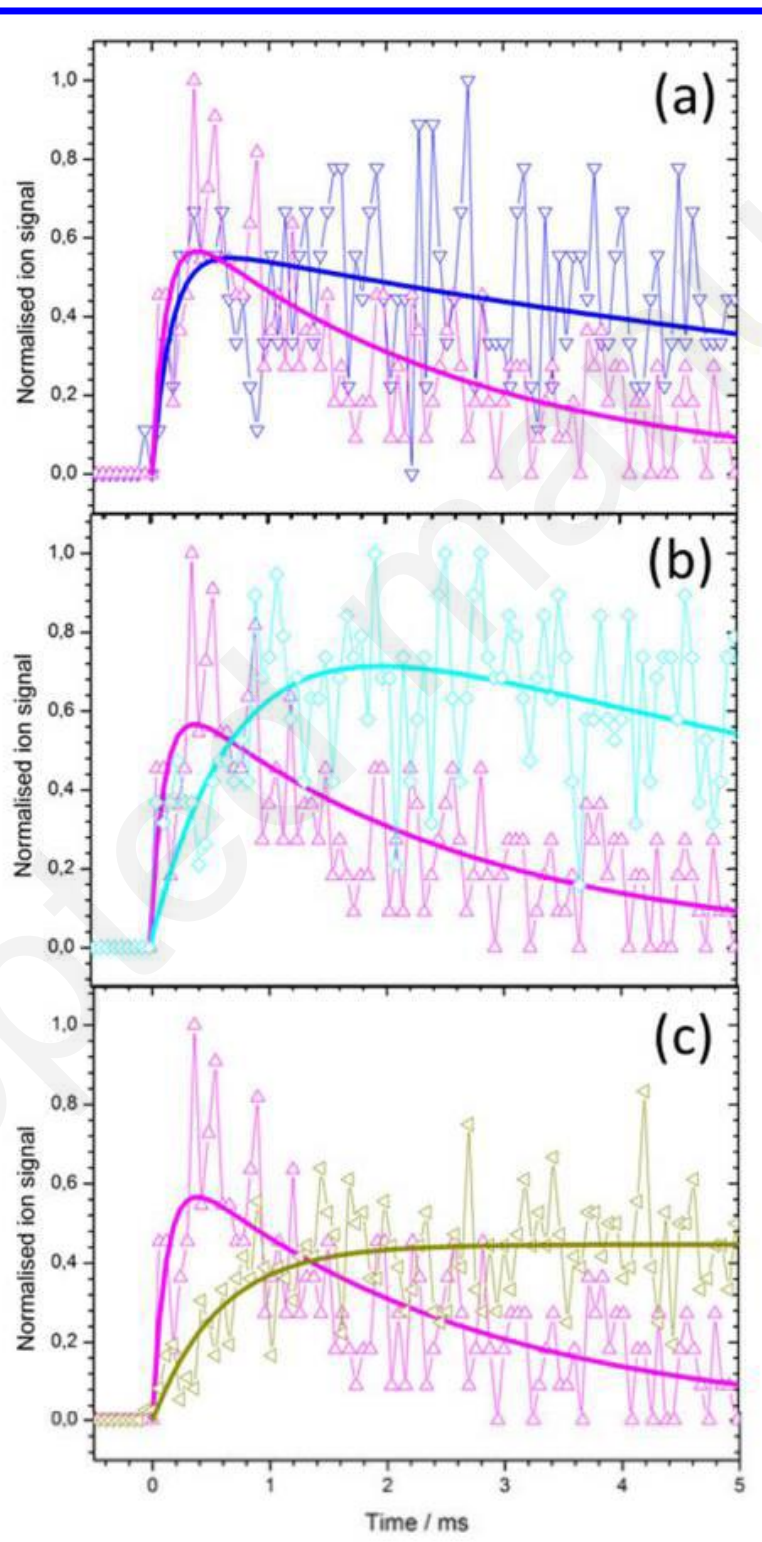

FIG. 3. Normalized kinetic traces obtained by photolysis of a $\mathrm{CBr}_{4}$ and trans-but-2-ene mixture in helium, at $9.0 \mathrm{eV}$ photon energy of (a) $\mathrm{m} / \mathrm{z} 53$ (blue down triangles) \& 67 (purple 

triangles) (b) $m / z 55$ (cyan diamonds) \& 67 (purple triangles) and (c) $m / z 68$ (dark yellow left triangles) \& 67 (purple triangles). Thick blue, cyan \& purple lines are double exponential fits to $\mathrm{m} / z 53,55 \& 67$ respectively. The thick dark yellow line is a single exponential fit to $\mathrm{m} / z$

68.

From the above analysis, $\mathrm{C}_{5} \mathrm{H}_{7}$ and $\mathrm{C}_{4} \mathrm{H}_{5}$ isomers are likely to be the primary products of the $\mathrm{C}\left({ }^{3} \mathrm{P}\right)+$ butene reaction through $\mathrm{H}$-elimination and $\mathrm{CH}_{3}$-elimination. The branching ratio between these two channels can be estimated directly from the values of $S_{i}^{\prime}$ obtained from the fit of the temporal traces corrected by the relative ionization cross sections and the mass discrimination factor. As these cross sections are unknown, they are assumed to be equal. Consequently, the ratio of the $S_{i}^{\prime}$ values gives only an estimate of the $\mathrm{H}-\mathrm{vs}$. $\mathrm{CH}_{3}-\mathrm{loss}$ branching. The fit of the $\mathrm{m} / z, 53$ and 67 temporal signals suggests a $0.63: 1 \quad \mathrm{C}_{4} \mathrm{H}_{5} / \mathrm{C}_{5} \mathrm{H}_{7}$ branching ratio. No data were recorded at photon energies above the IE of methyl radical $(9.83 \mathrm{eV}),{ }^{74}$ although it is expect it is formed.

FIG. 4 displays the $\mathrm{m} / \mathrm{z} 53$ photoionization spectrum obtained by irradiating the $\mathrm{CBr}_{4}$ and trans-but-2-ene mixture at $248 \mathrm{~nm}$. The data are integrated over the $0-40 \mathrm{~ms}$ time range and displayed from 7.4 to $9.0 \mathrm{eV}$ photon energy. Within the experimental uncertainty, the absence of an ion signal onset at $7.55 \mathrm{eV}$ suggests that the $i-\mathrm{C}_{4} \mathrm{H}_{5}$ isomer is not formed by the $\mathrm{C}\left({ }^{3} \mathrm{P}\right)+$ trans-but-2-ene reaction. ${ }^{57}$ The ion onset at $7.9 \mathrm{eV}$ suggests the presence of one or both of the methylpropargyl isomers $\left(\mathrm{IE}=7.94 \mathrm{eV}\right.$ for $\mathrm{H}_{2} \mathrm{CCCCH}_{3}$ and $\mathrm{IE}=7.95 \mathrm{eV}$ for $\left.\mathrm{HCCCHCH}_{3}\right) .{ }^{57}$ Within the experimental photon energy resolution $(40 \mathrm{meV})$ it is not possible to differentiate between the two methylpropargyl isomers. FIG. 4 also displays the integrated Franck-Condon factor simulations for the $i-\mathrm{C}_{4} \mathrm{H}_{5}$ (dashed cyan line) and methylpropargyl isomers (dashed and dotted blue \& dotted green lines). The spectra for each isomer are normalized to unity at $9.0 \mathrm{eV}$, because the simulated spectra are constant above this photon 
energy. The thick red line is the simulated spectrum of the methylpropargyl isomer $\mathrm{H}_{2} \mathrm{CCCCH}_{3}$ normalized to the experimental data. The data are well reproduced with no contribution from $i-\mathrm{C}_{4} \mathrm{H}_{5}$. The absence of the $i-\mathrm{C}_{4} \mathrm{H}_{5}$ isomer and the formation of one or both methylpropargyl isomers differs from previous studies on $\mathrm{C}_{4} \mathrm{H}_{5}$ formation. ${ }^{26,57}$

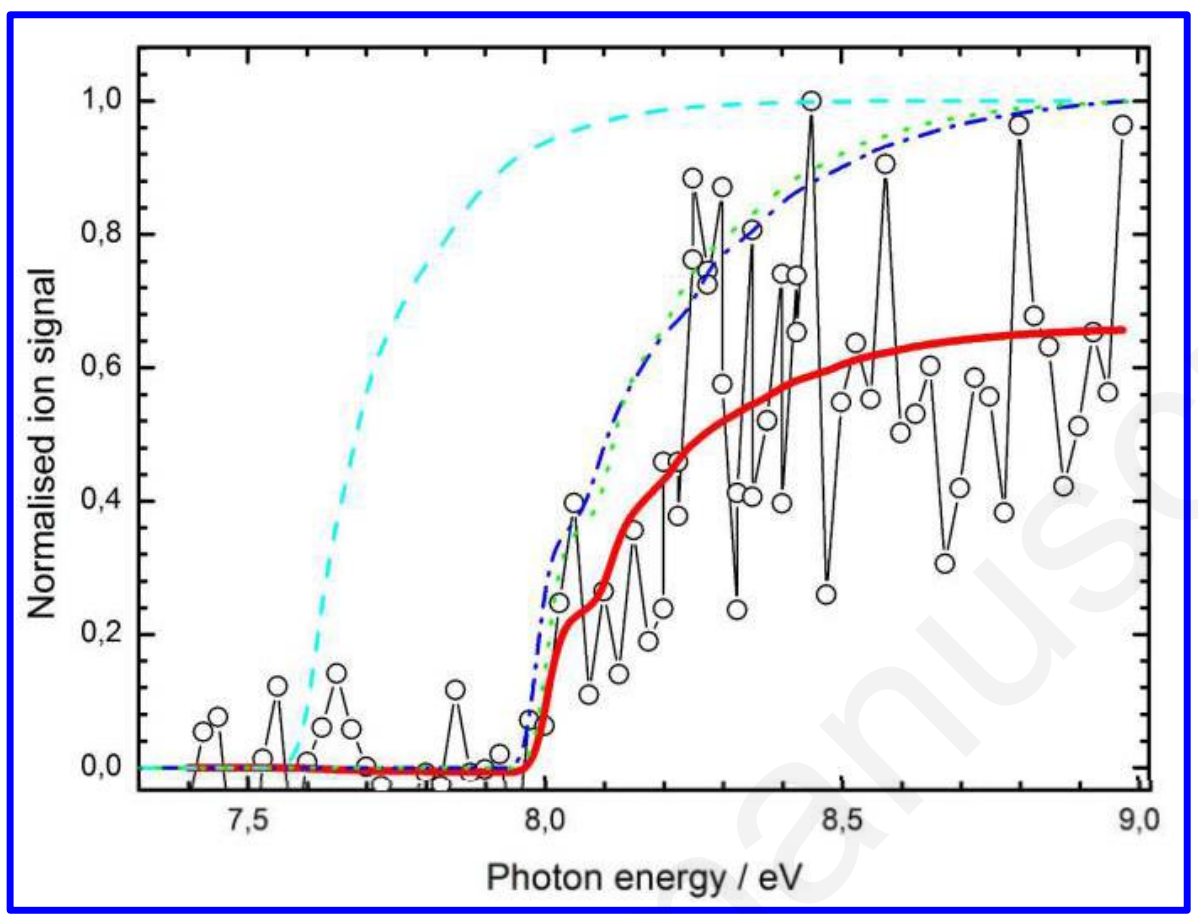

FIG. 4. Photoionization spectrum of $\mathrm{m} / \mathrm{z} 53$ obtained by photolysis of a $\mathrm{CBr}_{4}$ and trans-but-2-ene mixture in helium integrated over the 0-40 ms time range and displayed from 7.4 to $9.0 \mathrm{eV}$ photon energy. The lines are the integrated Franck-Condon factor simulations for $i-\mathrm{C}_{4} \mathrm{H}_{5}$ (dash cyan line) and methylpropargyl isomers $\left(\mathrm{H}_{2} \mathrm{CCCCH}_{3}\right.$ dashed-doted blue line $\& \mathrm{HCCCHCH}_{3}$ doted green lines). The thick red line is the integrated Franck-Condon factor simulation of $\mathrm{H}_{2} \mathrm{CCCCH}_{3}$ normalized to the experimental data.

Due to small signal-to-noise-ratio in the photoionization spectrum at $\mathrm{m} / \mathrm{z} 67$ it is not possible to infer the contribution from the various $\mathrm{C}_{5} \mathrm{H}_{7}$ isomers. The faster decay of this signal compared with $\mathrm{m} / \mathrm{z}=53$ makes the $\mathrm{C}_{5} \mathrm{H}_{7}$ spectra much noisier. However, the detection of ion signal above $7.5 \mathrm{eV}$ is consistent with the possible formation of the dimethylpropargyl isomers as suggested by Bergeat \& Loison $^{23}$ and Li et al. ${ }^{54}$ 
In FIG. 3, the decay rate of the $\mathrm{m} / \mathrm{z} 67$ signal $\left(428 \mathrm{~s}^{-1}\right)$ is greater than that of the $\mathrm{m} / \mathrm{z}$ 53 signal $\left(42 \mathrm{~s}^{-1}\right)$. From the product identification above, these signals are likely to be due to ionization of dimethylpropargyl and methylpropargyl. The presence of a methyl group on either terminal carbon of the propargyl radical may result in hyperconjugation ${ }^{75}$ between the partially filled $p$ orbital and the $\sigma$ orbital from a $\mathrm{C}-\mathrm{H}$ bond in beta position. Although hyperconjugation stabilizes the radical site, it weakens the methyl $\mathrm{C}-\mathrm{H}$ bond, facilitating $\mathrm{H}-$ abstraction by $\mathrm{Br}$ or $\mathrm{H}$ atoms. The large difference in decay rate between the two radicals could be due to the dependence of the hyperconjugation strength on the isomeric structure of the substituted propargyl radical and the number of methyl groups. Abstraction of a H-atom from dimethylpropargyl is consistent with the detection of a signal at $\mathrm{m} / \mathrm{z} 66$ with a slow formation rate (not shown). Within the experimental signal-to-noise, no signal is detected at $\mathrm{m} / \mathrm{z} 52$.

Photoionization spectra were also recorded for secondary products, m/z 55 and 68 (not shown here). The presence of an ion onset at ca. $7.5 \mathrm{eV}$ for $\mathrm{m} / \mathrm{z} 55$ suggests the contribution of one or two 1-methylallyl isomers $\left(\mathrm{C}_{4} \mathrm{H}_{7}\right){ }^{76}$ They are likely formed by abstraction of an $\mathrm{H}$ atom from butene by reactive species such as $\mathrm{Br}, \mathrm{CBr}$, or $\mathrm{H}^{76}$ The presence of an ion onset at $8.8 \mathrm{eV}$ in the photoionization spectrum for $\mathrm{m} / \mathrm{z} 68$ suggests its identification as isoprene. ${ }^{54}$

\section{B. $\mathbf{C}\left({ }^{3} \mathbf{P}\right)+c i s$-but-2-ene}

The mass spectrum registered (not shown here) following photolysis of a $\mathrm{CBr}_{4}$ and cis-but-2ene mixture in helium and nitrogen leads to the observation of the same four major peaks $\mathrm{m} / \mathrm{z}$ 53, 55, $67 \& 68$ as for trans-but-2-ene. FIG. 5 shows the normalized temporal traces of (a) $m / z 53$ (blue down triangles) and 67 (purple triangles) (b) $m / z 55$ (cyan diamonds) and 67 (purple triangles) and (c) $\mathrm{m} / \mathrm{z} 68$ (dark yellow left triangles) and 67 (purple triangles). Thick blue, cyan and purple lines are double exponential fits to $\mathrm{m} / \mathrm{z} 53,55$ and 67 respectively. The 
thick dark yellow line is a single exponential fit to $\mathrm{m} / \mathrm{z}$ 68. The first-order rise of $\mathrm{m} / \mathrm{z} 53$ and 67, around $3000-4000 \mathrm{~s}^{-1}$, suggests that they are primary reaction products as for the reaction of $\mathrm{C}\left({ }^{3} \mathrm{P}\right)$ with trans-but-2-ene. The first-order rise coefficients of $\mathrm{m} / \mathrm{z} 55$ and 68 , are 1230 and $1386 \mathrm{~s}^{-1}$, suggesting products formed by secondary or slower reactions. The fit of the $m / z 53$ and 67 signals from FIG. 5 lead to a $0.60: 1 \mathrm{C}_{4} \mathrm{H}_{5} / \mathrm{C}_{5} \mathrm{H}_{7}$ branching ratio.

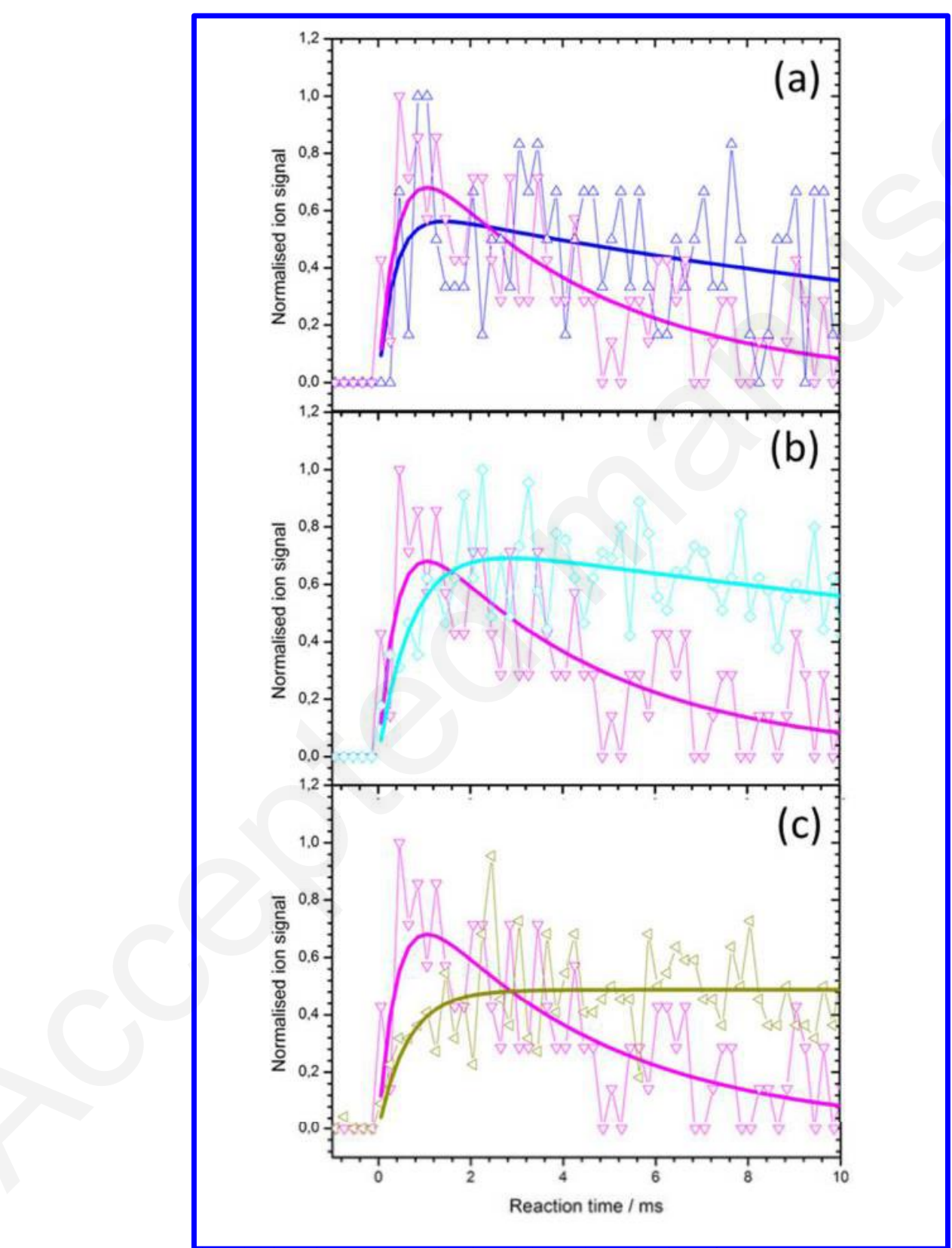

FIG. 5. Normalized kinetic traces obtained by photolysis of a CBr4 and cls-but-2-ene mixture in helium, at $9.0 \mathrm{eV}$ photon energy of (a) $\mathrm{m} / \mathrm{z} 53$ (blue down triangles) \& 67 (purple triangles) 
(b) $m / z 55$ (cyan diamonds) \& 67 (purple triangles) and (c) $m / z, 68$ (dark yellow left triangles) \& 67 (purple triangles). Thick blue, cyan \& purple lines are double exponential fits to $\mathrm{m} / \mathrm{z} 53$, $55 \& 67$ respectively. The thick dark yellow line is a single exponential fit to $m / z 68$.

FIG. 6 displays the $\mathrm{m} / z 53$ photoionization spectrum obtained by irradiating a $\mathrm{CBr}_{4}$ and cis-but-2-ene mixture at $248 \mathrm{~nm}$. The data are integrated over the 0-40 ms time range and displayed from 7.4 to $8.8 \mathrm{eV}$ photon energy. Similar to the results for trans-but-2-ene, there is no evidence for $i-\mathrm{C}_{4} \mathrm{H}_{5}$ isomer, and clear evidence for one or both methyl propargyl isomers.

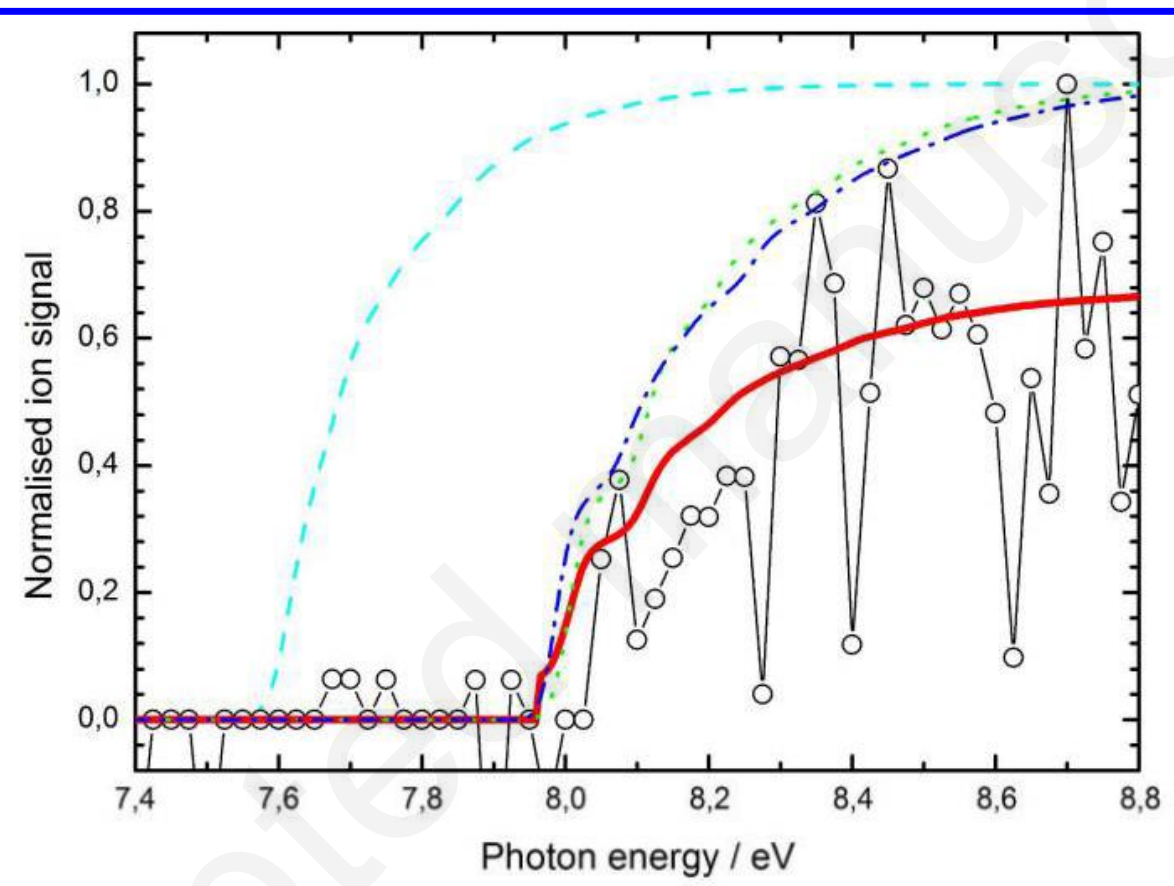

FIG. 6. Photoionization spectrum of $\mathrm{m} / z 53$ obtained by photolysis of a $\mathrm{CBr}_{4}$ and cis-but-2ene mixture in helium integrated over the $0-40 \mathrm{~ms}$ time range and displayed from 7.4 to 8.8 $\mathrm{eV}$ photon energy. The lines are the integrated Franck-Condon factor simulations for $i$ - $\mathrm{C}_{4} \mathrm{H}_{5}$ (dash cyan line) and methylpropargyl isomers $\left(\mathrm{H}_{2} \mathrm{CCCCH}_{3}\right.$ dashed-doted blue line \& $\mathrm{HCCCHCH}_{3}$ doted green lines). The thick red line is the integrated Franck-Condon factor simulation of $\mathrm{H}_{2} \mathrm{CCCCH}_{3}$ normalized to the experimental data.

FIG. 7 displays the $\mathrm{m} / \mathrm{z} 67$ photoionization spectrum obtained by irradiating a $\mathrm{CBr}_{4}$ and cis-but-2-ene mixture at $248 \mathrm{~nm}$. The red solid line represents the normalized integrated 
Franck Condon factors of the dimethylpropargyl isomer while the dashed line is that of the ethylpropargyl isomer. The relatively good match between the dimethylpropargyl simulated spectrum and experimental spectrum suggests that dimethylpropargyl is formed by the reaction. Due to the low signal however, it is not possible to determine the contribution from the ethylpropargyl isomer to the signal.

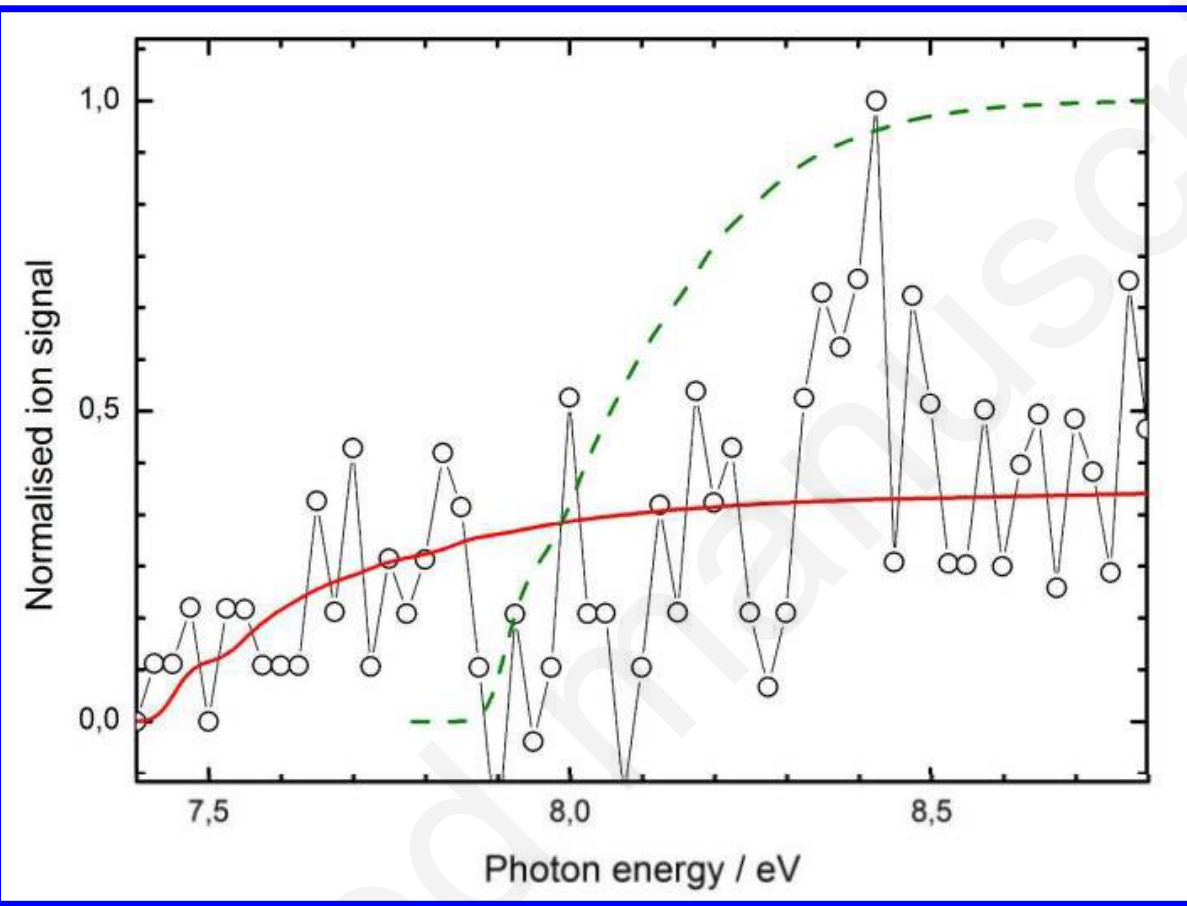

FIG. 7. Photoionization spectrum of $\mathrm{m} / \mathrm{z} 67$ obtained by photolysis of a $\mathrm{CBr}_{4}$ and cis-but-2ene mixture in helium integrated over the $0-40 \mathrm{~ms}$ time range and displayed from 7.4 to 8.8 $\mathrm{eV}$ photon energy. The thick red line and the dash green line are the integrated FranckCondon factor simulation for dimethylpropargyl (red line) and ethylpropargyl (green line) respectively.

\section{C. $\left.\mathbf{C}^{3} \mathbf{P}\right)+$ but-1-ene}

FIG. 8 displays a time resolved mass spectrum obtained by photolysis of a $\mathrm{CBr}_{4}$ and but-1-ene mixture in helium and nitrogen at $9.0 \mathrm{eV}$ photon energy from -2.5 to $35 \mathrm{~ms}$ relative to the laser pulse. The main time-resolved signals are observed at $m / z 39,55,66,67$ and 68 . By contrast with experiments performed with cis- and trans-but-2-ene, $\mathrm{m} / \mathrm{z} 53$ is not 

observed, and signals at m/z 29 and 39 appear after the photolysis laser pulse. Experiments performed while doubling the concentrations of all the reactants (not shown here) led to similar kinetic traces. As for the reaction with trans- $\mathrm{C}_{4} \mathrm{H}_{8}$, signals at $\mathrm{m} / \mathrm{z} 55$ and 68 are identified as methylallyl and isoprene. Signal at m/z 29, 39 and 67 are likely to originate from ionization of $\mathrm{C}_{2} \mathrm{H}_{5}, \mathrm{C}_{3} \mathrm{H}_{3}$, and $\mathrm{C}_{5} \mathrm{H}_{7}$ respectively, corresponding to the $\mathrm{C}_{3} \mathrm{H}_{3}+\mathrm{C}_{2} \mathrm{H}_{5}$ and $\mathrm{H}+$ $\mathrm{C}_{5} \mathrm{H}_{7}$ exit channels of the $\mathrm{C}\left({ }^{3} \mathrm{P}\right)+$ but-1-ene reaction. Signal at $\mathrm{m} / \mathrm{z} 66$ could come from abstraction of a hydrogen atom from $\mathrm{m} / \mathrm{z} 67$ as discussed in Section IV A. The signal at $\mathrm{m} / \mathrm{z}$ 39 is clearly identified as propargyl radical due to an ion onset at the propargyl ionization energy $(\mathrm{IE}=8.70 \mathrm{eV})$ and clear autoionization resonances. ${ }^{77}$ It should be noted, that when the concentration of butene is increased, the signal at $\mathrm{m} / \mathrm{z} .29$ is not observed anymore, while the signal at $m / z \quad 39$ is still present. This is likely due to fast reaction of the $\mathrm{C}_{2} \mathrm{H}_{5}$ radical, produced by the $\mathrm{C}\left({ }^{3} \mathrm{P}\right)+$ butene reaction, with butene. This is consistent with the fact that $\mathrm{C}_{2} \mathrm{H}_{5}$ reactions with hydrocarbons are expected to be faster than reactions with the resonance stabilized propargyl $\left(\mathrm{C}_{3} \mathrm{H}_{3}\right)$ radical (see KIDA datasheet at http://kida.obs.u-bordeaux1.fr/).

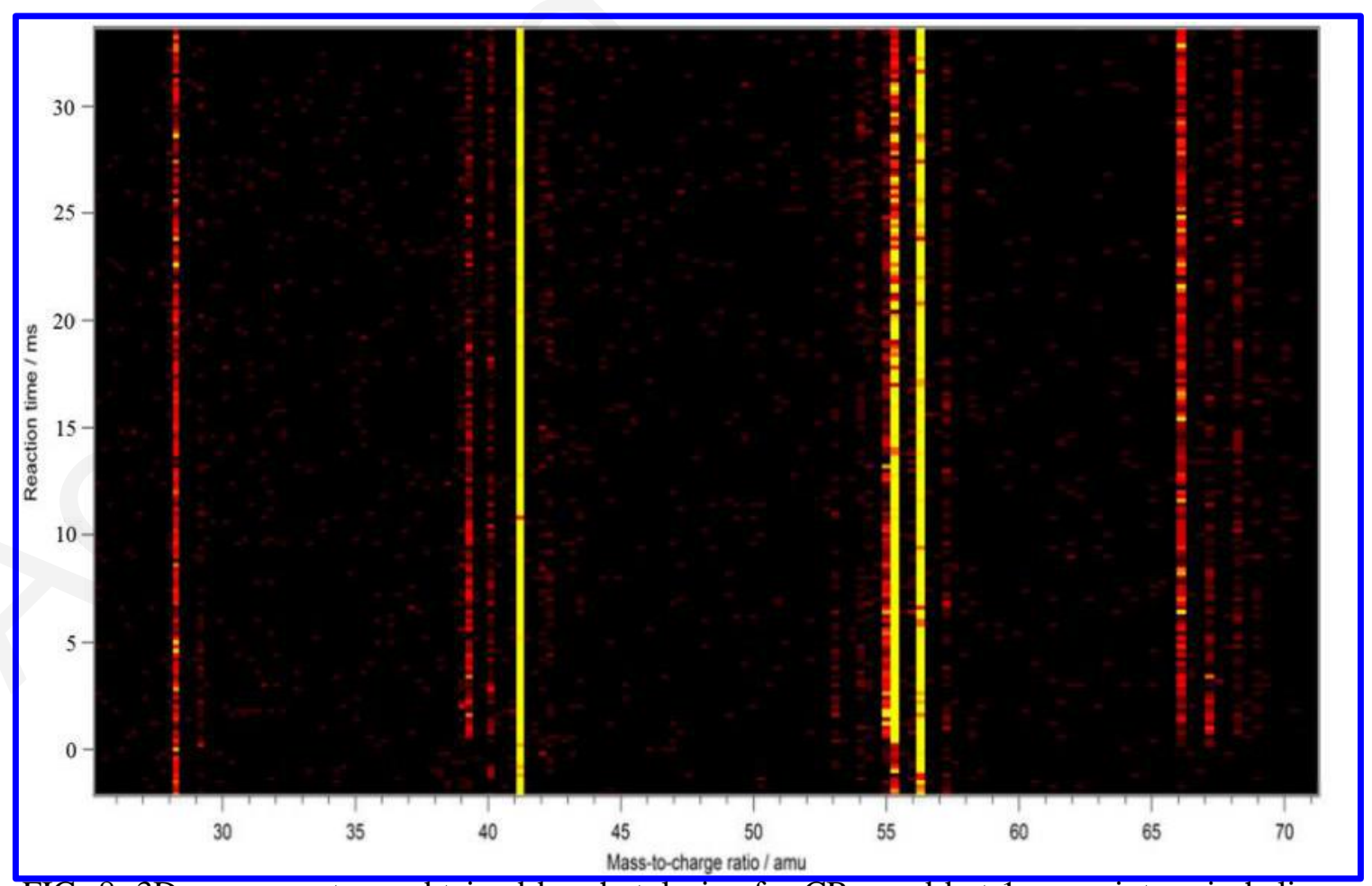

FIG. 8. 3D mass spectrum obtained by photolysis of a $\mathrm{CBr}_{4}$ and but-1-ene mixture in helium 
at $9.0 \mathrm{eV}$ photon energy from -2.5 to $35 \mathrm{~ms}$ relatively to the laser pulse.

FIG. 9 displays the $\mathrm{m} / \mathrm{z} 67$ photoionization spectrum obtained by irradiating a $\mathrm{CBr}_{4}$ and but-1-ene mixture in helium and nitrogen at $248 \mathrm{~nm}$. The data are integrated over the 0$40 \mathrm{~ms}$ time range and displayed from 7.4 to $8.8 \mathrm{eV}$ photon energy. The green dashed line is the integrated Franck-Condon factor simulation for ethylpropargyl and the thick red line that for dimethylpropargyl. The reasonable match between the integrated Franck-Condon factor simulation for ethylpropargyl and the experimental data suggests that ethylpropargyl is the main $\mathrm{C}_{5} \mathrm{H}_{7}$ isomer formed by the reaction $\mathrm{C}\left({ }^{3} \mathrm{P}\right)+$ but-1-ene. The product branching ratio for the $\mathrm{C}_{3} \mathrm{H}_{3} / \mathrm{C}_{5} \mathrm{H}_{7}$ isomers can be estimated directly from the ratio of their ion signals assuming equal ionization cross sections. The $\mathrm{m} / \mathrm{z}, 39$ and 67 signals from the mass spectrum lead to a 1:0.95 branching ratio for the $\mathrm{C}_{3} \mathrm{H}_{3}+\mathrm{C}_{2} \mathrm{H}_{5}$ and $\mathrm{H}+\mathrm{C}_{5} \mathrm{H}_{7}$ exit channels.

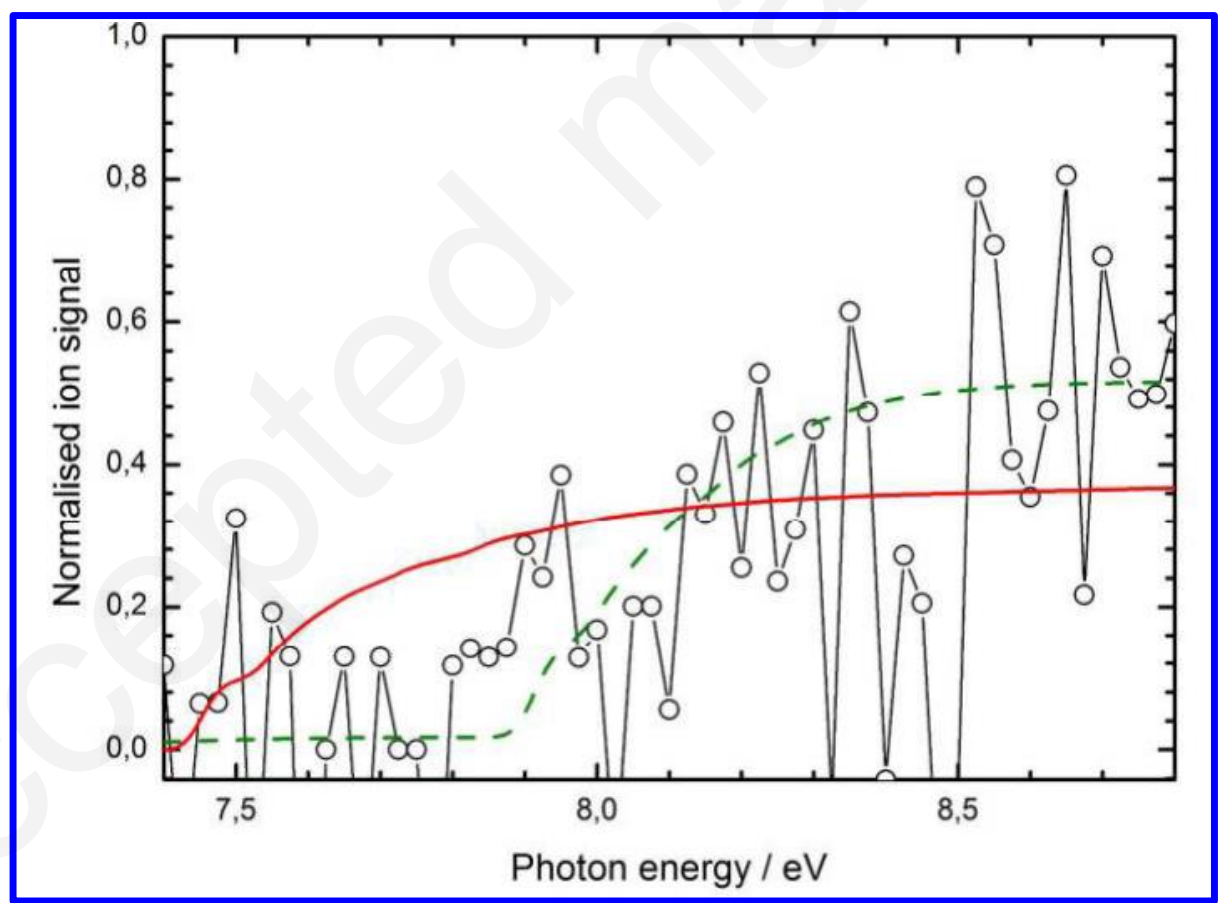

FIG. 9. Photoionization spectrum of $\mathrm{m} / \mathrm{z} 67$ obtained by photolysis of a $\mathrm{CBr}_{4}$ and but-1-ene mixture in helium integrated over the $0-40 \mathrm{~ms}$ time range and displayed from 7.4 to $8.8 \mathrm{eV}$ photon energy. The thick red line and the dash green line are the integrated Franck-Condon factor simulation for dimethylpropargyl (red line) and ethylpropargyl (green line) 
respectively.

\section{DISCUSSION}

For the $\mathrm{C}\left({ }^{3} \mathrm{P}\right)$ reactions with the trans- and cis-but-2-ene isomers, assuming equal ionization cross sections for the $\mathrm{C}_{4} \mathrm{H}_{5}$ and $\mathrm{C}_{5} \mathrm{H}_{7}$ isomers, $\mathrm{C}_{4} \mathrm{H}_{5}: \mathrm{C}_{5} \mathrm{H}_{7}$ branching ratios are found to be $0.63: 1$ and $0.60: 1$ ratio, respectively. This suggests that the stereoisomery has no effect on the product ratios. The results for the trans-but-2-ene isomer differs from the $0.33 \pm 0.06$ absolute $\mathrm{H}$-atom production branching fraction measured in fast flow reactor monitoring $\mathrm{H}$-atom fluorescence by Loison and Bergeat ${ }^{23}$ corresponding to a 1:0.5 $\mathrm{C}_{4} \mathrm{H}_{5}: \mathrm{C}_{5} \mathrm{H}_{7}$ branching ratio. Li et al. propose a possible 1:1 branching fraction based solely on the energetics of the products and transition states. ${ }^{54}$ Previous work on branching fraction for the $\mathrm{C}\left({ }^{3} \mathrm{P}\right)+\mathrm{C}_{3} \mathrm{H}_{6}$ reaction led to reasonable agreement between our results using tunable VUV photoionization with time of flight mass spectrometry and those obtained Loison and Bergeat using $\mathrm{H}$ atom fluorescence detection. ${ }^{26}$ The discrepancy reported here could be due to the low signal in the present experiments for the $\mathrm{C}_{5} \mathrm{H}_{7}$ isomers combined with the assumed equivalence of the photoionization cross section of these isomers. For these reasons the values reported by Loison and Bergeat ${ }^{23}$ are likely to be more accurate. For the $\mathrm{C}\left({ }^{3} \mathrm{P}\right)$ reaction with but-1-ene, the 1:0.95 branching fraction for the $\mathrm{C}_{3} \mathrm{H}_{3}: \mathrm{C}_{5} \mathrm{H}_{7}$ isomers derived from our experiments suggests similar probability of losing a $\mathrm{H}$ or $\mathrm{C}_{2} \mathrm{H}_{5}$ group from the initial $\mathrm{C}_{5} \mathrm{H}_{8}$ reaction adduct. No experimental or theoretical values are available for comparison.

$\mathrm{C}_{5} \mathrm{H}_{7}$ production, corresponding to the $\mathrm{H}$ elimination channel, is observed for all three $\mathrm{C}\left({ }^{3} \mathrm{P}\right)+$ butene isomer reactions. In the case of the $\mathrm{C}\left({ }^{3} \mathrm{P}\right)+$ trans-but-2-ene reaction, the theoretical investigation by $\mathrm{Li}$ et al. suggests that dimethylpropargyl $\left(\mathrm{CH}_{3} \mathrm{CHCCCH}_{3}\right)$ is the most likely isomer produced. Although this cannot not be confirmed by the present study for the $\mathrm{C}\left({ }^{3} \mathrm{P}\right)+$ trans-but-2-ene reaction, the fit of the photoionization spectrum presented in FIG. 7 is consistent with the formation of the dimethylpropargyl isomer by the $\mathrm{C}\left({ }^{3} \mathrm{P}\right)+$ cis-but-2- 
nene reaction. Regarding the $\mathrm{C}\left({ }^{3} \mathrm{P}\right)+$ but- 1 -ene reaction, the photoionization spectrum in FIG. 9 suggests ethylpropargyl as the main product isomer.

FIG. 10 presents a proposed mechanism for the direct formation of the dimethylpropargyl and ethylpropargyl isomers from $\mathrm{C}\left({ }^{3} \mathrm{P}\right)$ reactions with the butene isomers. As previously proposed ${ }^{26}$ the carbon atom is likely to interact with the $\pi$-electron system of the unsaturated hydrocarbon to form a 3-carbon ring. In the case of but-2-ene, different stereoisomers of the cyclic intermediate will be formed by reaction with the cis- or trans-but2 -ene. The strained isomer is likely to have a very short life time $(<1 \mathrm{ps})$ as suggested by Loison et $a .^{23}$ for reaction with butene and Kaiser et al. for reaction with ethylene. ${ }^{16}$ Upon ring opening it will form a substituted triplet allene-like intermediate. Elimination of a hydrogen atom from one of the $\mathrm{C}-\mathrm{H}$ groups in alpha position to the triplet carbon leads to the formation of dimethylpropargyl for reaction with trans/cis-but-2-ene and ethylpropargyl with but-l-ene. The photoionization spectra at $\mathrm{m} / \mathrm{z} 67$ reported here are consistent with the previously discussed mechanism, although a more complex isomerization schemes could lead to other $\mathrm{C}_{5} \mathrm{H}_{7}$ isomers. The formation of the energetically accessible $\mathrm{HCCC}\left(\mathrm{CH}_{3}\right) \mathrm{CH}_{3}$ would require a $\mathrm{CH}_{3}$ transfer after formation of the cyclic intermediate.
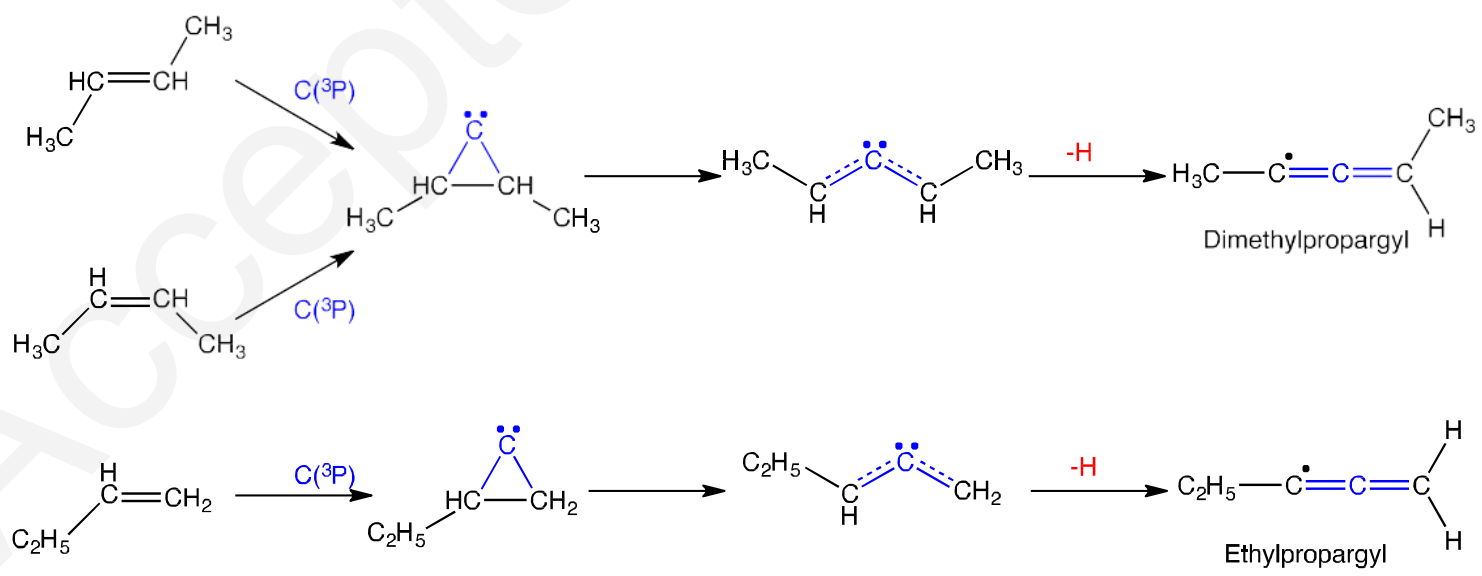

FIG. 10. Proposed mechanisms for the formation of $\mathrm{C}_{5} \mathrm{H}_{7}$ isomers from $\mathrm{C}(\stackrel{3}{\mathrm{P}})$ reactions with butene isomers. 
$\mathrm{C}_{4} \mathrm{H}_{5}$ isomers are observed for both $\mathrm{C}\left({ }^{3} \mathrm{P}\right)+$ trans- and cis-but-2-ene reactions, while they are not detected for the $\mathrm{C}\left({ }^{3} \mathrm{P}\right)+$ but-1-ene reaction. The absence of $\mathrm{C}_{4} \mathrm{H}_{5}$ products in the case of but-1-ene is consistent with the absence of a methyl group on the carbon double bond of the initial reactants. This suggests a rapid dissociation of the acyclic adduct through breaking of the $\mathrm{C}-\mathrm{H}$ or $\mathrm{C}-\mathrm{C}$ bonds initially on the $\mathrm{C}=\mathrm{C}$ group of the reactant without further isomerization. FIG. 11 shows the decomposition of the initial $\mathrm{C}_{5} \mathrm{H}_{8}$ adduct into ethyl + propargyl.

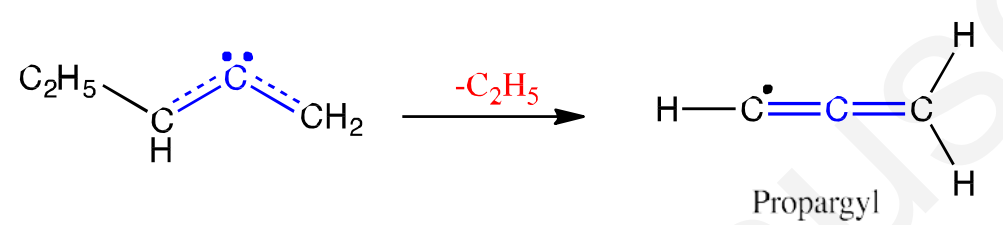

FIG. 11. Formation of propargyl radical from $\mathrm{C}_{2} \mathrm{H}_{5}$-loss from the $\mathrm{C}\left({ }^{3} \mathrm{P}\right)+$ but-1-ene reaction adducts.

Interestingly, in the case of $\mathrm{C}\left({ }^{3} \mathrm{P}\right)+$ trans- and cis-but-2-ene reactions where $\mathrm{C}_{4} \mathrm{H}_{5}$ is formed, the photoinization spectra, displayed in FIG. 4 and 6, differ significantly from those obtained for the $\mathrm{C}+\mathrm{C}_{3} \mathrm{H}_{6}$ reactions by Capron et al. ${ }^{26}$ or for fuel-rich flames experiments by Hansen et al. ${ }^{57}$ The main difference seems to be due to the absence of the $i-\mathrm{C}_{4} \mathrm{H}_{5}$ isomer $(\mathrm{IE}=7.55 \mathrm{eV}) .^{26}$ This contrast can be explained by the different loss channels of the intermediates formed by ring opening of the adducts from the $\mathrm{C}+$ propene or $\mathrm{C}+$ butene reactions. FIG. 12 displays the adduct formed by reaction of carbon atoms with cis-but-2-ene (top) and propene (bottom). In the case of the reaction with propene, the $i-\mathrm{C}_{4} \mathrm{H}_{5}$ isomers are formed directly by elimination of an $\mathrm{H}$-atom from the methyl group. ${ }^{26}$ In the case of $\mathrm{CH}_{3}$ loss from the $\mathrm{C}_{5} \mathrm{H}_{8}$ intermediate, the isomer formed by the most direct pathway is the $\mathrm{CH}_{3} \mathrm{CHCCH}$ methylpropargyl isomer. Formation of the $i-\mathrm{C}_{4} \mathrm{H}_{5}$ isomer would require a hydrogen transfer from the methyl group to a carbon in $\gamma$ position. Although within our experimental energy resolution it is not possible to distinguish between the two methylpropargyl isomers, the detection of one or both of the methylpropargyl isomers is 
consistent with mechanisms proposed by Loison \& Bergeat and Li et al. for the $\mathrm{C}\left({ }^{3} \mathrm{P}\right)$ reaction with trans-but-2-ene. $\mathrm{Li}$ et al. suggest $\mathrm{CH}_{3} \mathrm{CHCCH}$ as a likely candidate for $\mathrm{C}_{4} \mathrm{H}_{5}$ isomers from $\mathrm{C}+$ trans $-\mathrm{C}_{4} \mathrm{H}_{8}$ reaction due to either kinetic or thermodynamic factors. Indeed, from FIG. 12 formation of $\mathrm{CH}_{3} \mathrm{CCCH}_{2}$ would require a $\mathrm{H}$-atom transfer to a carbon in $\beta$ position. Distinguishing between the two isomers would be of interest as $\mathrm{CH}_{3} \mathrm{CHCCH}$ is completely absent from flames models whereas $\mathrm{CH}_{3} \mathrm{CCCH}_{2}$ is proposed to form toluene $\left(\mathrm{C}_{7} \mathrm{H}_{8}\right)$ or benzyl radical $\left(\mathrm{C}_{7} \mathrm{H}_{7}\right)$ by reaction with another $\mathrm{CH}_{3} \mathrm{CCH}_{2}$ or with propargyl radical. $^{58}$

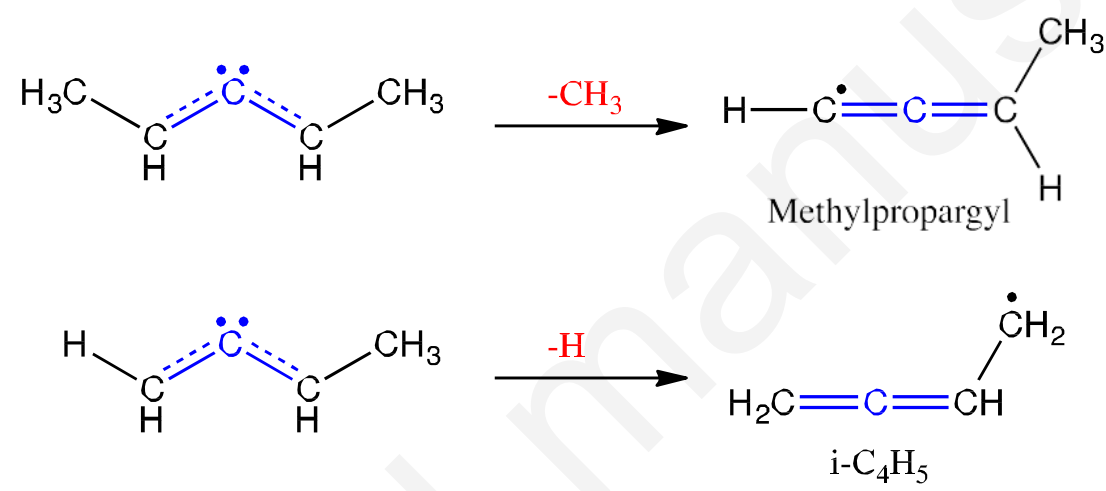

FIG. 12. Formation of $\mathrm{C}_{4} \mathrm{H}_{5}$ isomer from $\mathrm{CH}_{3}$ or $\mathrm{H}$-loss from the $\mathrm{C}\left({ }^{3} \mathrm{P}\right)+$ cis/trans-but-2-ene (top) and $\mathrm{C}+$ propene (bottom) reaction adducts. $^{29}$

Although carbon atoms may not be formed in standard flames and engines, they are known to be present in plasma and plasma-assisted environments. ${ }^{9-11}$ Similar to the $\mathrm{CH}$ radical, carbon atoms will react with the most abundant fuel molecules through addition/elimination pathways to form larger molecules. Such mechanisms still need to be validated, especially for large hydrocarbon molecules used as fuels. Coupling plasmas to combustion systems has the potential to greatly improve the combustion process through both an increase in combustion efficiency and a reduction in the emission of pollutants (e.g. NOx, $\mathrm{CO}_{2}$, soot). ${ }^{78}$ Feedback control algorithms using emission concentration as error signals and applied plasma as control signals could allow the combustion device to run at its stability limit. The design of such plasma-assisted technologies requires a basic understanding of the 
combined combustion and plasma chemistry leading to increased heat release and decreased emissions.

Isomers of the $\mathrm{C}_{4} \mathrm{H}_{5}$ and $\mathrm{C}_{5} \mathrm{H}_{7}$ hydrocarbon radicals have been detected in standard combustion flames where they contribute to the formation of larger molecules, including aromatic hydrocarbons. ${ }^{58,79}$ Their detection from the $\mathrm{C}\left({ }^{3} \mathrm{P}\right)+$ butene isomers reactions suggests that the formation of these radicals will be enhanced under plasma assisted combustion conditions potentially changing the molecular growth chemical scheme. The estimated branching ratios obtained in the present experiments are important data for the design of new combustion models under high-energy conditions such as those found in plasma. Ultimately these models will be used to tailor new combustion strategies with lower emission and higher efficiency.

Carbon-containing molecules can take various forms such as carbon chain molecules, polycyclic aromatic hydrocarbons (PAHs), carbon clusters and carbonaceous solids. ${ }^{80} \mathrm{C}\left({ }^{3} \mathrm{P}\right)$ atoms have been detected in dense interstellar clouds ${ }^{81-83}$ where a large fraction of the observed interstellar molecules are formed. None of the $\mathrm{C}_{4} \mathrm{H}_{8}$ isomers however, have been observed so far, likely due to their low electric dipole moments $(\leq 0,5 \mathrm{D})$. Their predicted abundances in astrochemical models, formed through $\mathrm{C}$ and $\mathrm{C}^{+}$reactions, seems to be sensitive to reactions involving atomic oxygen and nitrogen. ${ }^{84}$ In methane rich atmospheres such as Titan's, hydrocarbon formation is initiated by the photochemistry of methane that produces more complex and less saturated hydrocarbons. ${ }^{47,48,85-88}$ Although $\mathrm{C}_{4} \mathrm{H}_{8}$ has not been detected in Titan's atmosphere, ${ }^{47}$ Lavvas and coworkers ${ }^{48}$ for instance, included the reaction of carbon with 1-butene isomer in their photochemical model of Titan's atmosphere with no information on the products. Zhang et al. ${ }^{6}$ used a 1D-photochemical model of Titan to produce an atomic carbon profile reproducing the atomic carbon emission at $1657 \AA$ observed by the Cassini Ultra-violet Imaging Spectrograph and stress the need of a full set of 
photochemical reactions involving chemical species containing at least three carbon atoms to describe carbon atom chemistry above $600 \mathrm{~km}$. Recently, Dobrijevic and coworkers ${ }^{88}$ derived abundance profiles from a 1D-photochemical model coupling neutral and ion chemistries, showing that $\mathrm{C}_{4} \mathrm{H}_{8}$ (with no isomer distinction) is among the most abundant $\mathrm{C}_{4} \mathrm{H}_{\mathrm{x}}$ species above $600 \mathrm{~km}$. Such large hydrocarbons could also play a role in the formation of organic hazes observed in Titan's atmosphere. ${ }^{89}$

The rate coefficient of the reaction $\mathrm{C}\left({ }^{3} \mathrm{P}\right)$ trans-but-2-ene was measured by Loison et al. at room temperature $\left(k=1.9 \times 10^{-10} \mathrm{~cm}^{3} \text { molecules } \mathrm{s}^{-1} \mathrm{~s}^{-1}\right)^{23}$ and is likely to be of the same order of magnitude for cis-but-2-ene and but-1-ene. A large number of reactions between ground state carbon atoms and small saturated or unsaturated hydrocarbons have been shown to be fast at room temperature ${ }^{12,23,33,40,90}$ with rate coefficients increasing with decreasing temperature. ${ }^{13,14,91}$ Similarly, it is expected that reactions of $\mathrm{C}\left({ }^{3} \mathrm{P}\right)$ with butene isomers remain fast down to very low temperatures. Furthermore, the present investigation shows that even for such a simple system, the title reaction can form quite a large number of hydrocarbon radicals such as $\mathrm{C}_{4} \mathrm{H}_{5}$ isomers $\left(\mathrm{H}_{2} \mathrm{CCCCH}_{3}\right.$ and/or $\left.\mathrm{HCCCHCH}_{3}\right)$, propargyl $\left(\mathrm{C}_{3} \mathrm{H}_{3}\right)$, dimethylpropargyl and ethylpropargyl. Although the methyl radical is not detected it is expected to be formed by reaction of carbon atoms with trans- and cis-butene. The nature and branching ratios of these radicals are found to depend on the $\mathrm{C}_{4} \mathrm{H}_{8}$ isomers considered, and are consistent with simple addition/elimination schemes shown in Figs.10 - 12. All these radicals are susceptible to participate in the formation and destruction of other molecules present in these environments. This stresses the importance of including molecular isomer resolution for both reactants and products in interstellar astrochemical and atmospheric photochemical models in order to estimate their abundances as well as their potential importance in chemical schemes leading to the formation and destruction of complex molecules. 


\section{CONCLUSION}

The ground state $\mathrm{C}\left({ }^{3} \mathrm{P}\right)$ reactions with butene isomers (but-1-ene, cis-but-2-ene, transbut-2-ene) were studied under multiple collision conditions ${ }^{26}$ at $353 \mathrm{~K}$ and 4 Torr using tunable photoionization coupled to time-of-flight mass spectrometry. Products from secondary or side reactions are distinguished from primary products using the temporal profile of the detected ions. The reactions are performed under multiple collision conditions from 4 to 8 Torr with no significant pressure dependence of the product distributions. Although the initial energized adduct is expected to have a very short lifetime $(<1 \mathrm{ps}),{ }^{16,23}$ statistical calculations have shown that some of its isomers may have longer lifetime, up to tens of nanoseconds for intermediates of the $\mathrm{C}\left({ }^{3} \mathrm{P}\right)+\mathrm{C}_{2} \mathrm{H}_{2}$ reaction for instance. ${ }^{18}$ Experimental or theoretical studies over a wider range of pressure are required to fully investigate the effect of collisional quenching on the final product distribution and the role of intersystem crossing.

In the case of $\mathrm{C}\left({ }^{3} \mathrm{P}\right)+$ trans-but-2-ene and $\mathrm{C}\left({ }^{3} \mathrm{P}\right)+$ cis-but-2-ene reactions, the observed reaction exit channels are $\mathrm{C}_{4} \mathrm{H}_{5}+\mathrm{CH}_{3}$ and $\mathrm{C}_{5} \mathrm{H}_{7}+\mathrm{H}$. Assuming similar ionization cross sections for the $\mathrm{CH}_{3}$ - and $\mathrm{H}$-coproducts, the $\mathrm{C}_{4} \mathrm{H}_{5}: \mathrm{C}_{5} \mathrm{H}_{7}$ branching ratios are 0.63:1 and 0.60:1 for reactions with trans- and cis-2-butene, respectively. These values differ from the 1:0.5 $\mathrm{CH}_{3}: \mathrm{H}$-loss ratio measured in fast flow reactor $^{23}$ or the $1: 1$ ratio suggested by Li et al. ${ }^{54}$ from the analysis of the $\mathrm{C}_{5} \mathrm{H}_{8}$ potential energy surface. The difference between the experimental branching ratios is likely to be in part due to the absence of data on the photoionization cross sections for the $\mathrm{C}_{5} \mathrm{H}_{7}$ and $\mathrm{C}_{4} \mathrm{H}_{5}$ isomers. Further experimental or theoretical studies are required to obtain $\mathrm{C}_{4} \mathrm{H}_{5}$ and $\mathrm{C}_{5} \mathrm{H}_{7}$ photoionization cross-section and therefore more accurate branching ratios.

For the $\left.\mathrm{C}^{3} \mathrm{P}\right)+$ but- 1 -ene reaction, the observed reaction channels are $\mathrm{C}_{3} \mathrm{H}_{3}+\mathrm{C}_{2} \mathrm{H}_{5}$ and $\mathrm{C}_{5} \mathrm{H}_{7}+\mathrm{H}$. The measured $\mathrm{C}_{3} \mathrm{H}_{3}: \mathrm{C}_{5} \mathrm{H}_{7}$ signal ratio from the present flow data is found to 
be 1:0.95 assuming equal photoionization cross sections for the $\mathrm{C}_{3} \mathrm{H}_{3}$ and $\mathrm{C}_{5} \mathrm{H}_{7}$ radicals. No $\mathrm{C}_{4} \mathrm{H}_{5}$ formation is observed for this reaction. The non-detection of $\mathrm{C}_{4} \mathrm{H}_{5}$ for reaction with butl-ene is consistent with direct addition of the carbon atom onto the carbon double bond followed by rapid ring opening to form a triplet allene-like structure. The most likely fate of the energized intermediate is a $\mathrm{C}-\mathrm{C}$ bond breaking in $\beta$ position from the carbene center. In the case of reaction with but- $l$-ene, this direct addition-elimination mechanism leads to the formation of the observed $\mathrm{C}_{2} \mathrm{H}_{5}$ and $\mathrm{C}_{3} \mathrm{H}_{3}$ radicals.

Photoionization spectra at the mass of the $\mathrm{C}_{4} \mathrm{H}_{5}$ isomers for the trans and cis isomers show formation of one or both methylpropargyl isomers and negligible formation of $i-\mathrm{C}_{4} \mathrm{H}_{5}$. Within the experimental energy resolution, it is not possible to distinguish between the two methylpropargyl isomers. Photoionization spectra at the mass of the $\mathrm{C}_{5} \mathrm{H}_{7}$ isomers display very low signal-to-noise ratio and do not allow the unequivocal identification of the formed isomers. The detection of signal below $7.8 \mathrm{eV}$ is consistent with the formation of dimethylpropargyl for reaction with the trans and cis isomers. In the case of the reaction with but-1-ene, the photoionization spectrum is well reproduced by the simulated spectrum of only ethylpropargyl.

Overall, the isomer-resolved product detection for the $\mathrm{C}\left({ }^{3} \mathrm{P}\right)+$ butene isomer reactions is consistent with the addition of the carbon atom to the double bond to form a cyclic intermediate. This intermediate is likely to have a very short lifetime and to isomerize through ring opening to a triplet allene-like intermediate. The experimental data can all be explained using direct $\mathrm{H}-, \mathrm{CH}_{3}-$, or $\mathrm{C}_{2} \mathrm{H}_{5}$-elimination without further isomerization of the energized intermediates. Experimental and theoretical determinations of open-shell molecule photoionization cross-sections are required in order to improve the accuracy of branching ratios inferred from photoionization mass spectrometry studies. The reaction of ground state carbon atoms with butene isomers in carbon rich environments such as the ISM or plasma 
assisted combustion is therefore likely to contribute to the formation of large carbon radicals and therefore to molecular growth chemical schemes.

\section{ACKNOWLEDGEMENTS}

The Rennes team acknowledges support from the Agence Nationale de la Recherche, contract ANR-11-BS04-024-CRESUSOL-01, the French INSU/CNRS Program "Physique et Chimie du Milieu Interstellaire” (PCMI), the Institut National de Physique (INP CNRS), the Région Bretagne and the Université de Rennes 1. S.D.L.P. acknowledges financial support from the Institut Universitaire de France. Acknowledgement is made to the Donors of the American Chemical Society Petroleum Research Fund (PRF\#53105-DN16) for partial support of this research (F.G. and M.S.). We thank Mr Howard Johnsen for technical support of this experiment. D.L.O. and the instrumentation for this work are supported by the Division of Chemical Sciences, Geosciences, and Biosciences, the Office of Basic Energy Sciences, the U.S. Department of Energy. Sandia is a multi-program laboratory operated by Sandia Corporation, a Lockheed Martin Company, for the National Nuclear Security Administration under contract DE-AC04-94-AL85000. This research used resources of the Advanced Light Source, a DOE Office of Science User Facility, which is supported by the Direct, Office of Science, Office of Basic Energy Sciences, the U.S. Department of Energy under contract DEAC02-05CH11231 at Lawrence Berkeley National Laboratory. 


\section{REFERENCES}

(1) Ingalls, J. G.; Bania, T. M.; Jackson, J. M. Atomic carbon in the high-latitude molecular cloud MBM-12. Astrophys. J. 1994, 431, L139-L142.

(2) Ingalls, J. G.; Chamberlin, R. A.; Bania, T. M.; Jackson, J. M.; Lane, A. P.; Stark, A. A. Atomic carbon in southern hemisphere high-latitude clouds. Astrophys. J. 1997, 479, 296302.

(3) Van der Veen, W.; Huggins, P. J.; Matthews, H. E. Atomic carbon in the circumstellar envelopes of evolved stars. Astrophys. J. 1998, 505, 749-755.

(4) Sofia, U. J.; Cardelli, J. A.; Guerin, K. P.; Meyer, D. M. Carbon in the diffuse interstellar medium. Astrophys. J. 1997, 482, L105-L108.

(5) Wilson, C. D. Atomic carbon emission from individual molecular clouds in M33. Astrophys. J. 1997, 487, L49-L52.

(6) Zhang, X.; Ajello, J. M.; Yung, Y. L. Atomic carbon in the upper atmosphere of Titan Astrophys. J. Lett. 2010, 708, L18-L21.

(7) McElroy, M. B.; McConnel, J. C. Atomic carbon in atmospheres of Mars and Venus $J$. Geophys. Res. 1971, 76, 6674-6690.

(8) Ajello, J. M.; Gustin, J.; Stewart, I.; Larsen, K.; Esposito, L.; Pryor, W.; McClintock, W.; Stevens, M. H.; Malone, C. P.; Dziczek, D. Titan airglow spectra from the Cassini Ultraviolet Imaging Spectrograph: FUV disk analysis. Geophys. Res. Lett. 2008, 35, L06102 1-5. (9) Belikov, A. E.; Sakhapov, S. Z.; Smith, M. A.; Tikhonov, G. Mass spectrometry of molecules and radicals in glow discharge plasma. J. Eng. Thermophys. 2011, 20, 42-54. (10) Benedikt, J.; Wisse, M.; Woen, R. V.; Engeln, R.; van de Sanden, M. C. M. Role of carbon atoms in the remote plasma deposition of hydrogenated amorphous carbon. J. Appl. Phys. 2003, 94, 6932-6938. 
(11) Yu, B. W.; Girshick, S. L. Atomic carbom vapor as a diamond growth precursor in thermal plasmas. J. Appl. Phys. 1994, 75, 3914-3923.

(12) Haider, N.; Husain, D. Absolute rate data for the reactions of ground-state atomic carbon, C $2 \mathrm{p}^{2}\left({ }^{3} \mathrm{P}_{\mathrm{J}}\right)$, with alkenes investigated by time-resolved atomic resonance-absorption spectroscopy in the vacuum ultraviolet J. Chem. Soc., Faraday 1993, 89, 7-14.

(13) Chastaing, D.; James, P. L.; Sims, I. R.; Smith, I. W. M. Neutral-neutral reactions at the temperatures of interstellar clouds: Rate coefficients for reactions of atomic carbon, $\mathrm{C}\left({ }^{3} \mathrm{P}\right)$, with $\mathrm{O}_{2}, \mathrm{C}_{2} \mathrm{H}_{2}, \mathrm{C}_{2} \mathrm{H}_{4}$ and $\mathrm{C}_{3} \mathrm{H}_{6}$ down to 15 K. Phys. Chem. Chem. Phys. 1999, 1, 2247-2256. (14) Chastaing, D.; Le Picard, S. D.; Sims, I. R.; Smith, I. W. M.; Geppert, W. D.; Naulin, C.; Costes, M. Rate coefficients and cross-sections for the reactions of $\mathrm{C}\left({ }^{3} \mathrm{P}_{\mathrm{J}}\right)$ atoms with methylacetylene and allene. Chem. Phys. Lett. 2000, 331, 170-176.

(15) Clary, D. C.; Haider, N.; Husain, D.; Kabir, M. Interstellar carbon-chemistry - Reactionrates of neutral atomic carbon with organic-molecules Astrophys. J. 1994, 422, 416-422.

(16) Kaiser, R. I.; Lee, Y. T.; Suits, A. G. Crossed-beam reaction of $\mathrm{C}\left({ }^{3} \mathrm{PJ}_{\mathrm{J}}\right)$ with $\mathrm{C}_{2} \mathrm{H}_{2}\left({ }^{1} \Sigma^{+}\right.$z Observation of tricarbon-hydride $\mathrm{C}_{3}$ H. J. Chem. Phys. 1995, 103, 10395-10398.

(17) Takayanagi, T. Quantum dynamics study on the product branching for the $\mathrm{C}\left({ }^{3} \mathrm{P}\right)+\mathrm{C} \underset{2}{\mathrm{H}}{ }_{2}$ reaction: cyclic- $\mathrm{C}_{3} \mathrm{H}$ versus linear-C $\mathrm{C}_{3} \mathrm{H}$. J. Phys. Chem. A 2006, 110, 361-366.

(18) Mebel, A. M.; Kislov, V. V.; Hayashi, M. Prediction of product branching ratios in the $\mathrm{C}\left({ }^{3} \mathrm{P}\right)+\mathrm{C}_{2} \mathrm{H}_{2} \rightarrow 1-\mathrm{C}_{3} \mathrm{H}+\mathrm{H} / \mathrm{c}-\mathrm{C}_{3} \mathrm{H}+\mathrm{H} / \mathrm{C}_{3}+\mathrm{H}_{2}$ reaction using ab initio coupled clusters calculations extrapolated to the complete basis set combined with Rice-Ramsperger-Kassel-

Marcus and radiationless transition theories. J. Chem. Phys. 2007, 126, 204310 1-11.

(19) Kaiser, R. I.; Lee, Y. T.; Suits, A. G. Crossed-beam reaction of carbon atoms with hydrocarbon molecules .1. Chemical dynamics of the propargyl radical formation $\mathrm{C}_{3} \mathrm{H}_{3}$ $\left(\mathrm{X}^{2} \mathrm{~B}_{2}\right)$, from reaction of $\mathrm{C}\left({ }^{3} \mathrm{P}_{\mathrm{J}}\right)$ with ethylene, $\mathrm{C}_{2} \mathrm{H}_{4}\left(\mathrm{X}^{1} \mathrm{~A}_{\mathrm{g}}\right)$. J. Chem. Phys. 1996, 105, 87058720. 
(20) Leonori, F.; Petrucci, R.; Segoloni, E.; Bergeat, A.; Hickson, K. M.; Balucani, N.; Casavecchia, P. Unraveling the dynamics of the $\mathrm{C}\left({ }^{3} \mathrm{P},{ }^{1} \mathrm{D}\right)+\mathrm{C}_{2} \mathrm{H}_{2}$ reactions by the crossed molecular beam scattering technique. J. Phys. Chem. A 2008, 112, 1363-1379.

(21) Kaiser, R. I.; Mebel, A. M.; Chang, A. H. H.; Lin, S. H.; Lee, Y. T. Crossed-beam reaction of carbon atoms with hydrocarbon molecules. V. Chemical dynamics of n- $\mathrm{C}_{4} \mathrm{H}_{3}$ formation from reaction of $\mathrm{C}\left({ }^{3} \mathrm{PJ}_{\mathrm{J}}\right)$ with allene, $\mathrm{H}_{2} \mathrm{CCCH}_{2}\left(\mathrm{X}^{1} \mathrm{~A}_{1}\right)$. J. Chem. Phys. 1999, 110, 10330-10344.

(22) Schranz, H. W.; Smith, S. C.; Mebel, A. M.; Lin, S. H. Prediction of absolute rate coefficients and product branching ratios for the $\mathrm{C}\left({ }^{3} \mathrm{P}\right)$ plus allene reaction system. J. Chem. Phys. 2002, 117, 7055-7067.

(23) Loison, J. C.; Bergeat, A. Reaction of carbon atoms, $\mathrm{C}\left(2 \mathrm{p}^{2},{ }^{3} \mathrm{P}\right)$ with $\mathrm{C}_{3} \mathrm{H}_{4}$ (allene and methylacetylene), $\mathrm{C}_{3} \mathrm{H}_{6}$ (propylene) and $\mathrm{C}_{4} \mathrm{H}_{8}$ (trans-butene): Overall rate constants and atomic hydrogen branching ratios. Phys. Chem. Chem. Phys. 2004, 6, 5396-5401. (24) Mebel, A. M.; Kaiser, R. I.; Lee, Y. T. Ab initio MO study of the global potential energy surface of $\mathrm{C}_{4} \mathrm{H}_{4}$ in triplet electronic state and the reactions of $\mathrm{C}^{3} \mathrm{PJ}_{\mathrm{J}}$ ) with $\mathrm{C}_{3} \mathrm{H}_{4}$ (allene and propyne) and $\mathrm{C}_{2}\left(\mathrm{~A}^{3} \Pi_{\mathrm{u}}\right)$ with $\mathrm{C}_{2} \mathrm{H}_{4}\left(\mathrm{X}^{1} \mathrm{~A}^{+}\right)$. J. Am. Chem. Soc. 2000, 122, 1776-1788. $1 \mathrm{~g}$

(25) Kaiser, R. I.; Nguyen, T. L.; Le, T. N.; Mebel, A. M. An ab initio investigation of reactions of carbon atoms $\mathrm{C}\left({ }^{3} \mathrm{P}_{\mathrm{J}}\right)$ with $\mathrm{C}_{2} \mathrm{H}_{4}$ and $\mathrm{C}_{3} \mathrm{H}_{6}$ in the interstellar medium. Astrophys. J. 2001, 561, 858-863.

(26) Capron, M.; Bourgalais, J.; Kailasanathan, R. K. A.; Osborn, D. L.; Le Picard, S. D.; Goulay, F. Flow tube studies of the $\mathrm{C}\left({ }^{3} \mathrm{P}\right)$ reactions with ethylene and propylene. Phys. Chem. Chem. Phys. 2015, 17, 23833-23846.

(27) Kaiser, R. I.; Stranges, D.; Bevsek, H. M.; Lee, Y. T.; Suits, A. G. Crossed-beam reaction of carbon atoms with hydrocarbon molecules .4. Chemical dynamics of 
methylpropargyl radical formation, $\mathrm{C}_{4} \mathrm{H}_{5}$, from reaction of $\left.\mathrm{C}^{3}{ }^{3} \mathrm{P}_{\mathrm{J}}\right)$ with propylene, $\mathrm{C}_{3} \mathrm{H}_{6}$ (X'A'). J. Chem. Phys. 1997, 106, 4945-4953.

(28) Chin, C. H.; Chen, W. K.; Huang, W. J.; Lin, Y. C.; Lee, S. H. Identification of $\mathrm{C}_{4} \mathrm{H}_{5}$, $\mathrm{C}_{4} \mathrm{H}_{4}, \mathrm{C}_{3} \mathrm{H}_{3}$ and $\mathrm{CH}_{3}$ radicals produced from the reaction of atomic carbon with propene: Implications for the atmospheres of Titan and giant planets and for the interstellar medium. Icarus 2013, 222, 254-262.

(29) Hahndorf, I.; Lee, Y. T.; Kaiser, R. I.; Vereecken, L.; Peeters, J.; Bettinger, H. F.; Schreiner, P. R.; Schleyer, P. V.; Allen, W. D.; Schaefer, H. F. A combined crossed-beam, ab initio, and Rice-Ramsperger-Kassel-Marcus investigation of the reaction of carbon atoms $\mathrm{C}\left({ }^{3} \mathrm{P}_{\mathrm{J}}\right)$ with benzene, $\mathrm{C}_{6} \mathrm{H}_{6}\left(\mathrm{X}^{1} \mathrm{~A}_{1 \mathrm{~g}}\right)$ and $\mathrm{d}(6)$-benzene, $\mathrm{C}_{6} \mathrm{D}_{6}\left(\mathrm{X}^{1} \mathrm{~A}_{1 \mathrm{~g}}\right)$. J. Chem. Phys. 2002, $116,3248-3262$.

(30) Sun, B. J.; Huang, C. Y.; Kuo, H. H.; Chen, K. T.; Sun, H. L.; Huang, C. H.; Tsai, M. F.; Kao, C. H.; Wang, Y. S.; Gao, L. G. et al. Formation of interstellar 2,4-pentadiynylidyne, $\operatorname{HCCCCC}\left(\mathrm{X}^{2} \Pi\right)$, via the neutral-neutral reaction of ground state carbon atom, $\mathrm{C}\left({ }^{3} \mathrm{P}_{\mathrm{J}}\right)$, with diacetylene, $\mathrm{HCCCCH}\left(\mathrm{X}^{1} \Sigma^{+}{ }_{\mathrm{g}}\right.$. J. Chem. Phys. 2008, 128, 244303 1-16.

(31) Bourgalais, J.; Capron, M.; Kailasanathan, R. K. A.; Osborn, D. L.; Hickson, K. M.; Loison, J. C.; Wakelam, V.; Goulay, F.; Le Picard, S. D. The $\mathrm{C}\left({ }^{3} \mathrm{P}\right)+\mathrm{NH}_{3}$ reaction in interstellar chemistry. I. Investigation of the product formation channels. Astrophys. J. 2015, 812, 1-12.

(32) Hickson, K. M.; Loison, J. C.; Bourgalais, J.; Capron, M.; Le Picard, S. D.; Goulay, F.; Wakelam, V. The $\mathrm{C}\left({ }^{3} \mathrm{P}\right)+\mathrm{NH}_{3}$ reaction in interstellar chemistry. II. Low temperture rate constants and modeling of $\mathrm{NH}, \mathrm{NH}_{2}$, and $\mathrm{NH}_{3}$ abundances in dense interstellar clouds. Astrophys. J. 2015, 812, 1-8. 
(33) Haider, N.; Husain, D. Kinetic investigation of the reactions of ground-state atomic carbon, $\mathrm{C}\left(2 \mathrm{p}^{2}\left({ }^{3} \mathrm{P}_{\mathrm{J}}\right)\right)$, with acetylenes by time-resolved atomic resonance - absorptionspectroscopy in the vacuum ultra-violet Ber. Bunsen-Ges. Phys. Chem.

Chem. Phys. 1992, 176, 133-150.

(34) Husain, D.; Ioannou, A. X. Collisional removal of atomic carbon, C $2 \mathrm{p}^{2}\left({ }^{3} \mathrm{P}_{\mathrm{J}}\right)$, by aldehydes and ketones, investigated by time-resolved atomic resonance absorption spectroscopy in the vacuum ultra-violet. J. Photochem. Photobiol., A 1999, 129, 1-7.

(35) Geppert, W. D.; Naulin, C.; Costes, M.; Capozza, G.; Cartechini, L.; Casavecchia, P.; Volpi, G. G. Combined crossed-beam studies of $\mathrm{C}\left({ }^{3} \mathrm{PJ}_{\mathrm{J}}\right)+\mathrm{C}_{2} \mathrm{H}_{4} \rightarrow \mathrm{C}_{3} \mathrm{H}_{3}+\mathrm{H}$ reaction dynamics between 0.49 and $30.8 \mathrm{~kJ} \mathrm{~mol}^{-1}$. J. Chem. Phys. 2003, 119, 10607-10617.

(36) Malik, M. A.; Hughes, D.; Malik, A.; Xiao, S.; Schoenbach, K. H. Study of the production of hydrogen and light hydrocarbons by spark discharges in diesel, kerosene, gasoline, and methane. Plasma Chem. and Plasma Process. 2013, 33, 271-279.

(37) Pascoli, G.; Polleux, A. Condensation and growth of hydrogenated carbon clusters in carbon-rich stars. Astron. Astrophys. 2000, 359, 799-810.

(38) Lee, Y. T. Molecular-beam studies of elementary chemical processes. Science 1987, 236, 793-798.

(39) Chin, C. H.; Chen, W. K.; Huang, W. J.; Lin, Y. C.; Lee, S. H. Exploring the dynamics of reaction $\mathrm{C}\left({ }^{3} \mathrm{P}\right)+\mathrm{C}_{2} \mathrm{H}_{4}$ with crossed beam/photoionization experiments and quantum chemical calculations. J. Phys. Chem. A 2012, 116, 7615-7622.

(40) Bergeat, A.; Loison, J. C. Reaction of carbon atoms, $\mathrm{C}\left(2 \mathrm{p}^{2},{ }^{3} \mathrm{P}\right)$ with $\mathrm{C}_{2} \mathrm{H}_{2}, \mathrm{C}_{2} \mathrm{H}_{4}$ and $\mathrm{C}_{6} \mathrm{H}_{6}$ : Overall rate constant and relative atomic hydrogen production. Phys. Chem. Chem. Phys. 2001, 3, 2038-2042. 
(41) Hickson, K. M.; Loison, J. C.; Wakelam, V. Temperature dependent product yields for the spin forbidden singlet channel of the $\mathrm{C}\left({ }^{3} \mathrm{P}\right)+\mathrm{C}_{6} \mathrm{H}_{2}$ reaction. Chem. Phys. Lett. 2016, 659, $70-75$.

(42) Bond, J. Q.; Alonso, D. M.; Wang, D.; West, R. M.; Dumesic, J. A. Integrated catalytic conversion of gamma-valerolactone to liquid alkenes for transportation fuels. Science $\mathbf{2 0 1 0}$, $327,1110-1114$.

(43) Mehl, M.; Pitz, W. J.; Westbrook, C. K.; Yasunaga, K.; Conroy, C.; Curran, H. J. Autoignition behavior of unsaturated hydrocarbons in the low and high temperature regions. Proc. Comb. Inst. 2011, 33, 201-208.

(44) Zhao, P.; Yuan, W. H.; Sun, H. Y.; Li, Y. Y.; Kelley, A. P.; Zheng, X. L.; Law, C. K. Laminar flame speeds, counterflow ignition, and kinetic modeling of the butene isomers. Proc. Comb. Inst. 2015, 35, 309-316.

(45) Zhang, Y. J.; Cai, J. H.; Zhao, L.; Yang, J. Z.; Jin, H. F.; Cheng, Z. J.; Li, Y. Y.; Zhang, L. D.; Qi, F. An experimental and kinetic modeling study of three butene isomers pyrolysis at low pressure. Combust. Flame 2012, 159, 905-917.

(46) Zhang, H. L.; Wu, W. D.; Gong, C. S.; Wang, W.; He, Z. B.; Li, J.; Ju, X.; Tang, Y. J.; Xie, E. Q. Structural and optical properties of Fe-doped hydrogenated amorphous carbon films prepared from trans-2-butene by plasma enhanced metal organic chemical vapor deposition. App. Phys. A 2010, 98, 895-900.

(47) Lavvas, P. P.; Coustenis, A.; Vardavas, I. M. Coupling photochemistry with haze formation in Titan's atmosphere, part I: Model description. Planet. Space Sci. 2008, 56, 27 -

66.

(48) Lavvas, P. P.; Coustenis, A.; Vardavas, I. M. Coupling photochemistry with haze formation in Titan's atmosphere, Part II: Results and validation with Cassini/Huygens data. Planet. Space Sci. 2008, 56, 67-99. 
(49) Atkinson, R.; Aschmann, S. M. Rate constants for the reaction of the OH radical with series of alkenes and dialkenes at 295 +/- 1 K. Int. J. Chem. Kinet. 1984, 16, 1175-1186. (50) Loison, J.-C.; Daranlot, J.; Bergeat, A.; Caralp, F.; Mereau, R.; Hickson, K. M. Gasphase kinetics of hydroxyl radical reactions with $\mathrm{C}_{3} \mathrm{H}_{6}$ and $\mathrm{C}_{4} \mathrm{H}_{8}$ : product branching ratios and $\mathrm{OH}$ addition site-specificity. J. Phys. Chem. A 2010, 114, 13326-13336.

(51) Bouwman, J.; Fournier, M.; Sims, I. R.; Leone, S. R.; Wilson, K. R. Reaction rate and isomer-specific product branching ratios of $\mathrm{C}_{2} \mathrm{H}+\mathrm{C}_{4} \mathrm{H}_{8}$ : 1-butene, cis-2-butene, trans-2butene, and isobutene at 79 K. J. Phys. Chem. A 2013, 117, 5093-5105.

(52) Nizamov, B.; Leone, S. R. Kinetics of $\mathrm{C}_{2} \mathrm{H}$ reactions with hydrocarbons and nitriles in the 104-296 K temperature range. J. Phys. Chem. A 2004, 108, 1746-1752.

(53) Laufer, A. H.; Fahr, A. Reactions and kinetics of unsaturated $\mathrm{C}_{2}$ hydrocarbon radicals. Chem. Rev. 2004, 104, 2813-2832.

(54) Li, Y.; Liu, H. L.; Huang, X. R.; Wang, D. Q.; Sun, C. C. Theoretical study of the C( $\left.{ }^{3} P\right)$ + trans- $\mathrm{C}_{4} \mathrm{H}_{8}$ reaction. J. Phys. Chem. A 2009, 113, 6800-6811.

(55) Miller, J. A.; Pilling, M. J.; Troe, E. Unravelling combustion mechanisms through a quantitative understanding of elementary reactions. Proc. Comb. Inst. 2005, 30, 43-88.

(56) McEnally, C. S.; Pfefferle, L. D.; Atakan, B.; Kohse-Hoeinghaus, K. Studies of aromatic hydrocarbon formation mechanisms in flames: Progress towards closing the fuel gap. Progress. Ener. Comb. Sci. 2006, 32, 247-294.

(57) Hansen, N.; Klippenstein, S. J.; Taatjes, C. A.; Miller, J. A.; Wang, J.; Cool, T. A.; Yang, B.; Yang, R.; Wei, L. X.; Huang, C. Q. et al. Identification and chemistry of $\mathrm{C}_{4} \mathrm{H}_{3}$ and $\mathrm{C}_{4} \mathrm{H}_{5}$ isomers in fuel-rich flames. J. Phys. Chem. A 2006, 110, 3670-3678. (58) Miller, J. A.; Melius, C. F. Kinetic and thermodynamic issues in the formation of aromatic-compounds in flames of aliphatic fuels. Combust. Flame 1992, 91, 21-39. 
(59) Melius, C. F.; Colvin, M. E.; Marinov, N. M.; Pitz, W. J.; Senkan, S. M. Reaction mechanisms in aromatic hydrocarbon formation involving the $\mathrm{C}_{5} \mathrm{H}_{5}$ cyclopentadienyl moiety; Combustion Institute: Pittsburgh, 1996.

(60) Miller, J. A. Theory and modeling in combustion chemistry; Combustion Institute: Pittsburgh, 1996.

(61) Osborn, D. L.; Zou, P.; Johnsen, H.; Hayden, C. C.; Taatjes, C. A.; Knyazev, V. D.; North, S. W.; Peterka, D. S.; Ahmed, M.; Leone, S. R. The multiplexed chemical kinetic photoionization mass spectrometer: A new approach to isomer-resolved chemical kinetics. Rev. Sci. Instrum. 2008, 79, 104103: 1-10.

(62) Taatjes, C. A.; Hansen, N.; Osborn, D. L.; Kohse-Hoeinghaus, K.; Cool, T. A.; Westmoreland, P. R. "Imaging" combustion chemistry via multiplexed synchrotronphotoionization mass spectrometry. Phys. Chem. Chem. Phys. 2008, 10, 20-34.

(63) Shannon, R. J.; Cossou, C.; Loison, J. C.; Caubet, P.; Balucani, N.; Seakins, P. W.; Wakelam, V.; Hickson, K. M. The fast $\mathrm{C}\left({ }^{3} \mathrm{P}\right)+\mathrm{CH}_{3} \mathrm{OH}$ reaction as an efficient loss process for gas-phase interstellar methanol. RSC Advances 2014, 4, 26342-26353.

(64) Vaghjiani, G. L. Kinetics of $\mathrm{CH}$ radicals with $\mathrm{O}_{2}$ : Evidence for $\mathrm{CO}$ chemiluminescence in the gas phase reaction. J. Chem. Phys. 2003, 119, 5388-5396.

(65) Hickson, K. M.; Loison, J.-C.; Lique, F.; Klos, J. An experimental and theoretical investigation of the $\mathrm{C}\left({ }^{1} \mathrm{D}\right)+\mathrm{N}_{2} \rightarrow \mathrm{C}\left({ }^{3} \mathrm{P}\right)+\mathrm{N}_{2}$ quenching reaction at low temperature. J. Phys. Chem. A 2016, DOI 10.1021/acs.jpca.6b00480.

(66) Le Picard, S. D.; Honvault, P.; Bussery-Honvault, B.; Canosa, A.; Laube, S.; Launay, J. M.; Rowe, B.; Chastaing, D.; Sims, I. R. Experimental and theoretical study of intramultiplet transitions in collisions of $\mathrm{C}\left({ }^{3} \mathrm{P}\right)$ and $\mathrm{Si}\left({ }^{3} \mathrm{P}\right)$ with He. J. Chem. Phys. 2002, 117, 10109-10120. 
(67) Es-sebbar, E. T.; Benilan, Y.; Farooq, A. Temperature-dependent absorption crosssection measurements of 1-butene $\left(1-\mathrm{C}_{4} \mathrm{H}_{8}\right)$ in VUV and IR. J. Quant. Spectrosc. Radiat. Transfer 2013, 115, 1-12.

(68) Barone, V.; Bloino, J.; Biczysko, M.; Santoro, F. Fully integrated approach to compute vibrationally resolved optical spectra: From small molecules to macrosystems. J. Chem. Theo. Comp. 2009, 5, 540-554.

(69) Simmie, J. M.; Somers, K. P. Benchmarking compound methods (CBS-QB3, CBSAPNO, G3, G4, W1BD) against the active thermochemical tables: A litmus test for costeffective molecular formation enthalpies. J. Phys. Chem. A 2015, 119, 7235-7246. (70) Ruzsicska, B. P.; Jodhan, A.; Choi, H. K. J.; Strausz, O. P.; Bell, T. N. Chemistry of carbynes - Reaction of CF, CCl, and CBr with alkenes. J. Am. Chem. Soc. 1983, 105, 24892490.

(71) Savee, J. D.; Welz, O.; Taatjes, C. A.; Osborn, D. L. New mechanistic insights to the $\mathrm{O}\left({ }^{3} \mathrm{P}\right)+$ propene reaction from multiplexed photoionization mass spectrometry. Phys. Chem. Chem. Phys. 2012, 14, 10410-10423.

(72) Keyser, L. F. High-pressure flow kinetics. A study of the $\mathrm{OH}+\mathrm{HCl}$ reaction from 2 to 100 torr. J. Phys. Chem. 1984, 88, 4750-4758.

(73) Bergeat, A.; Calvo, T.; Dorthe, G.; Loison, J. C. Fast-flow study of the CH plus CH reaction products. J. Phys. Chem. A 1999, 103, 6360-6365.

(74) Schulenburg, A. M.; Alcaraz, C.; Grassi, G.; Merkt, F. Rovibrational photoionization dynamics of methyl and its isotopomers studied by high-resolution photoionization and photoelectron spectroscopy. J. Chem. Phys. 2006, 125, 104310 1-10.

(75) Fleming, I. Frontier orbitals and organic chemical reactions; Wiley-Interscience West Sussex, Engalnd, 2006. 
(76) Lang, M.; Holzmeier, F.; Hemberger, P.; Fischer, I. Threshold photoelectron spectra of combustion relevant $\mathrm{C}_{4} \mathrm{H}_{5}$ and $\mathrm{C}_{4} \mathrm{H}_{7}$ isomers. J. Phys. Chem. A 2015, 119, 3995-4000.

(77) Savee, J. D.; Soorkia, S.; Welz, O.; Selby, T. M.; Taatjes, C. A.; Osborn, D. L. Absolute photoionization cross-section of the propargyl radical. J. Chem. Phys. 2012, 136, 134307 110.

(78) Ju, Y. G.; Sun, W. T. Plasma assisted combustion: Dynamics and chemistry. Progress. Ener. Comb. Sci. 2015, 48, 21-83.

(79) Yang, B.; Li, Y. Y.; Wei, L. X.; Huang, C. Q.; Wang, J.; Tian, Z. Y.; Yang, R.; Sheng, L. S.; Zhang, Y. W.; Qi, F. An experimental study of the premixed benzene/oxygen/argon flame with tunable synchrotron photoionization. Proc. Comb. Inst. 2007, 31, 555-563.

(80) Henning, T.; Salama, F. Carbon - Carbon in the universe. Science 1998, 282, 22042210 .

(81) Phillips, T. G.; Huggins, P. J. Abundance of atomic carbon (C) in dense interstellar clouds. Astrophys. J. 1981, 251, 533-540.

(82) Schilke, P.; Benford, D. J.; Hunter, T. R.; Lis, D. C.; Phillips, T. G. A line survey of Orion-KL from 607 to 725 GHz. Astrophys. J. Supp. Series 2001, 132, 281-364.

(83) Stark, R.; Wesselius, P. R.; vanDishoeck, E. F.; Laureijs, R. J. Neutral carbon in translucent regions of the dark cloud L 183. Astron. Astrophys. 1996, 311, 282-290.

(84) Loison, J. C.; Wakelam, V.; Hickson, K. M.; Bergeat, A.; Mereau, R. The gas-phase chemistry of carbon chains in dark cloud chemical models. Mon. Not. R. Astron. Soc. 2014, 437, 930-945.

(85) Vuitton, V.; Yelle, R. V.; Lavvas, P.; Klippenstein, S. J. Rapid association reactions at low pressure: impact on the formation of hydrocarbons in Titan. Astrophys. J. 2012, 744, 1-7. (86) Krasnopolsky, V. A. Chemical composition of Titan's atmosphere and ionosphere: Observations and the photochemical model. Icarus 2014, 236, 83-91. 
(87) Dobrijevic, M.; Hebrard, E.; Loison, J. C.; Hickson, K. M. Coupling of oxygen, nitrogen, and hydrocarbon species in the photochemistry of Titan's atmosphere. Icarus 2014, $228,324-346$.

(88) Dobrijevic, M.; Loison, J. C.; Hickson, K. M.; Gronoff, G. 1D-coupled photochemical model of neutrals, cations and anions in the atmosphere of Titan. Icarus 2016, 268, 313-339. (89) Woon, D. E.; Park, J. Y. Modeling chemical growth processes in Titan's atmosphere 2. Theoretical study of reactions between $\mathrm{C}_{2} \mathrm{H}$ and ethene, propene, 1-butene, 2-butene, isobutene, trimethylethene, and tetramethylethene. Icarus 2009, 202, 642-655.

(90) Haider, N.; Husain, D. The collisional behavior of ground-state atomic carbon, $\mathrm{C}\left(2 \mathrm{p}^{2}\left({ }^{3} \mathrm{P}_{\mathrm{J}}\right)\right)$, with unsaturated cyclic-compounds studied by time-resolved atomic resonanceabsorption spectroscopy in the vacuum ultra-violet Ber. Bunsen-Ges. Phys. Chem. Chem. Phys. 1993, 97, 571-577.

(91) Chastaing, D.; Le Picard, S. D.; Sims, I. R.; Smith, I. W. M. Rate coefficients for the reactions of $\mathrm{C}\left({ }^{3} \mathrm{P}_{\mathrm{J}}\right)$ atoms with $\mathrm{C}_{2} \mathrm{H}_{2}, \mathrm{C}_{2} \mathrm{H}_{4}, \mathrm{CH}_{3} \mathrm{C}=\mathrm{CH}$ and $\mathrm{H}_{2} \mathrm{C}=\mathrm{C}=\mathrm{CH}_{2}$ at temperatures down to 15 K. Astron. Astrophys. 2001, 365, 241-247. 
TOC Graphic

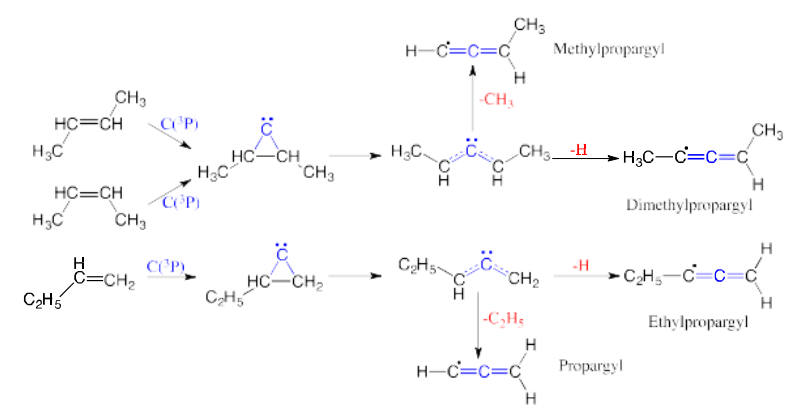

14

15

16

17

18

19

20

21

22

23

24

25

26

27

28

29

30

31

32

33

34

35

36

37

38

39

40

41

42

43

44

45

46

47

48

49

50

51

52

53

54

55

56

57

58

59

60 